\title{
Operational assimilation of ASCAT surface soil wetness at the Met Office
}

\author{
I. Dharssi ${ }^{1}$, K. J. Bovis ${ }^{2}$, B. Macpherson ${ }^{2}$, and C. P. Jones ${ }^{2}$ \\ ${ }^{1}$ Centre for Australian Weather and Climate Research, Australian Government Bureau of Meteorology, Melbourne, Australia \\ ${ }^{2}$ Met Office, Exeter, UK
}

Received: 1 March 2011 - Published in Hydrol. Earth Syst. Sci. Discuss.: 29 April 2011

Revised: 15 August 2011 - Accepted: 24 August 2011 - Published: 31 August 2011

\begin{abstract}
Currently, no extensive, near real time, global soil moisture observation network exists. Therefore, the Met Office global soil moisture analysis scheme has instead used observations of screen temperature and humidity. A number of new space-borne remote sensing systems, operating at microwave frequencies, have been developed that provide a more direct retrieval of surface soil moisture. These systems are attractive since they provide global data coverage and the horizontal resolution is similar to weather forecasting models. Several studies show that measurements of normalised backscatter (surface soil wetness) from the Advanced Scatterometer (ASCAT) on the meteorological operational (MetOp) satellite contain good quality information about surface soil moisture. This study describes methods to convert ASCAT surface soil wetness measurements to volumetric surface soil moisture together with bias correction and quality control. A computationally efficient nudging scheme is used to assimilate the ASCAT volumetric surface soil moisture data into the Met Office global soil moisture analysis. This ASCAT nudging scheme works alongside a soil moisture nudging scheme that uses observations of screen temperature and humidity. Trials, using the Met Office global Unified Model, of the ASCAT nudging scheme show a positive impact on forecasts of screen temperature and humidity for the tropics, North America and Australia. A comparison with in-situ soil moisture measurements from the US also indicates that assimilation of ASCAT surface soil wetness improves the soil moisture analysis. Assimilation of ASCAT surface soil wetness measurements became operational during July 2010.
\end{abstract}

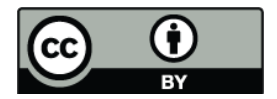

Correspondence to: I. Dharssi (i.dharssi@bom.gov.au)

\section{Introduction}

Soil moisture can have a significant impact on screen temperature and humidity, low clouds and precipitation by influencing the exchange of heat and water between the land surface and the atmosphere. Soil moisture can vary significantly over short distances so that measurements made at one location contain little information about neighbouring locations. The variability in soil moisture is due to the spatial distribution of rainfall and also the spatial variation of the soil texture, vegetation and topography. The high degree of spatial variability limits the utility of ground based point observations of soil moisture. Currently, no extensive global soil moisture observation network exists. Some regional near real-time soil moisture observing networks do exist, such as the USDA: SCAN (US Department of Agriculture: soil climate analysis network). The International Soil Moisture Network initiative is trying to establish and maintain a global in-situ soil moisture database (Dorigo et al., 2011).

Many numerical weather prediction (NWP) centres use observations of screen temperature and humidity to analyse soil moisture, e.g. the Met Office (Best and Maisey, 2002), ECMWF (Drusch and Viterbo, 2007), Meteo-France (Giard and Bazile, 2000) and the German Weather Service (Hess et al., 2008). Drusch and Viterbo (2007) have examined the performance of the ECMWF soil moisture nudging scheme that uses observations of screen temperature and humidity (they call it an optimal interpolation scheme) and concluded that soil moisture nudging significantly improves weather forecasts on large geographical domains. Temperature forecasts for the Northern Hemisphere were significantly improved for up to nine days and to a level of $700 \mathrm{hPa}$. However, by comparison with in-situ soil moisture observations from the Oklahoma mesonet they also conclude that soil moisture nudging fails to improve the analysis and forecasts of soil moisture itself. 
A number of new space-borne remote sensing systems, operating at microwave frequencies, have been developed that provide a more direct retrieval (than using screen level observations) of surface soil moisture, e.g. ASCAT (Advanced Scatterometer, C band, Bartalis et al., 2007), SMOS (Soil Moisture and Ocean Salinity, L band, Kerr et al., 2001), AMSR-E (Advanced Microwave Scanning Radiometer on the Earth Observing System, C and X band, Owe et al., 2008; Njoku et al., 2003) and WindSat (C and X band, Li et al., 2010). These systems are attractive since they provide global data coverage and the horizontal resolution is similar to global NWP models. At microwave frequencies the dielectric constant of liquid water $(\simeq 70)$ is much higher than that of the soil mineral particles $(<5)$ or ice. An increase in soil moisture leads to an increase in the dielectric constant of the soil which leads to a decrease in soil emissivity and an increase in soil reflectivity. Therefore, satellite based measurements of microwave brightness temperature (passive system) or backscatter (active system) can be used to derive estimates of surface soil moisture using a retrieval algorithm. However, using these additional sources of data is challenging since:

i. Microwave sensors only sense the top few $\mathrm{cms}$ of soil. NWP requires knowledge of soil moisture throughout the plant root zone, since plants extract soil water through their roots which then evaporates from their leaves.

ii. Satellite microwave measurements can also be affected by numerous other factors such as vegetation water content and single scattering albedo, soil roughness, topography, soil texture, salinity and surface temperature. Consequently, retrieval algorithms can produce very biased estimates of surface soil moisture, (Reichle et al., 2004). Intercomparison of several different retrieval algorithms for the passive microwave AMSR-E instrument find large differences in the quality of the retrieval algorithms (Draper et al., 2009; Rudiger et al., 2009; Jackson et al., 2010).

iii. Improvements to the parameters and processes in land surface models are likely to be necessary before assimilation of satellite derived soil moisture shows significant benefit. For example, the operational implementation of the Unified Model T/q soil moisture nudging scheme uncovered many deficiencies in the land surface model and prompted the work of Dharssi et al. (2009). This work resulted in large improvements to Unified Model (UM) forecasts of screen temperature and humidity through better specification of the UM soil physical properties.

This paper describes the assimilation of both satellite derived soil moisture and screen level observations of temperature and humidity for soil moisture analysis using a simple, computationally efficient method. Only a few other works have looked at assimilating together both remotely sensed data and screen level observations for soil moisture analysis (for example Draper et al., 2011; Albergel et al., 2010; de Rosnay et al., 2009; Seuffert et al., 2004). In addition, this paper is one of a few to examine the impact of assimilating satellite derived soil moisture on forecasts of screen temperature and humidity (other examples are Mahfouf, 2010; Scipal et al., 2008a; Drusch, 2007). The Met Office is the first to operationally use satellite derived soil moisture for numerical weather prediction. Although several other NWP centres are actively researching this area.

This work builds on the previous study of Scipal et al. (2008a), who examined the impact of assimilating ERS scatterometer derived soil moisture in the ECMWF NWP system. Three experiments were performed; a control (CTRL) where soil moisture is unconstrained and free-wheels, a test experiment (OI) with a soil moisture nudging scheme that uses observations of screen temperature and humidity and a second test experiment (NDG) that only uses ERS scatterometer derived soil moisture to nudge the model level 1 soil moisture. Scipal et al. (2008a) find that the NDG experiment provides better forecasts of screen temperature and humidity than the CTRL but poorer forecasts than the OI experiment. Our trials differ from Scipal et al. (2008a) in one crucial way; our test experiments use observations of screen temperature and humidity AND also ASCAT data to analyse the soil moisture. The UM T/q soil moisture nudging scheme that uses observations of screen temperature and humidity is applied first to correct the model soil moisture in all four soil layers. Next, ASCAT data is used to correct the model level 1 soil moisture (see Fig. 1). Our control experiments are like the OI experiment of Scipal et al. (2008a). No experiments are performed, in this study, where the model soil moisture is unconstrained and free-wheels (no soil moisture analysis). Free-wheeling is expected to show a degradation (as found by Scipal et al., 2008a; Draper et al., 2011). Our control experiment includes the T/q soil moisture nudging scheme and so is more difficult to improve upon than an experiment without any soil moisture analysis. The pertinent question to ask is, what is the added value of using satellite derived surface soil moisture measurements in addition to using screen level observation of temperature and humidity to analyse soil moisture for NWP.

Reichle et al. (2004) show that strong biases exist between satellite derived and model derived surface soil moisture. In addition, model simulated soil moisture values are highly model specific. For example, Koster et al. (2009) show that direct transfer of soil moisture values from one land surface model to a different land surface model is inappropriate and likely to lead to problems. Therefore, Reichle and Koster (2004) argue that the satellite derived surface soil moisture values must be bias corrected to be consistent with the model used for assimilation. The bias correction accounts for model assumptions such as those about soil texture and vegetation 


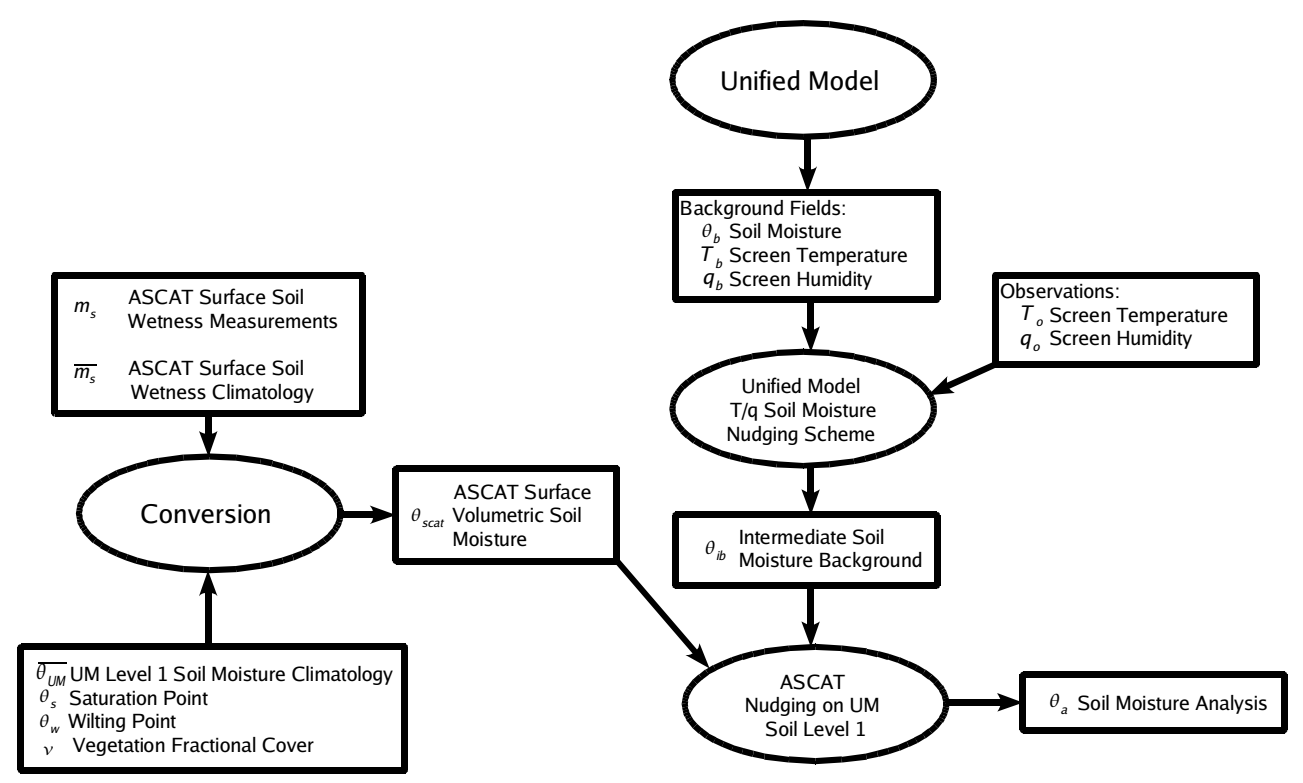

Fig. 1. Schematic view of the soil moisture analysis scheme used by the Test experiments in this study. The Test experiments use ASCAT surface soil wetness measurements and screen level temperature and humidity observations to analyse soil moisture.

parameters and the parametrisation of bare soil evaporation. Consequently, data assimilation of the bias corrected surface soil moisture is more likely to improve model surface fluxes and lead to better weather forecasts. Many studies use a bias correction technique called cumulative distribution function (CDF) matching (Reichle and Koster, 2004; Drusch et al., 2005) that requires a long time-series (at least one year) of satellite and model data. Any significant changes to the land surface model and/or satellite retrieval algorithm would necessitate a recalculation of the bias correction parameters.

Mahfouf (2010) provides a good explanation of the difficulty in obtaining appropriate long time-series of model and satellite data for the bias correction of the satellite derived surface soil moisture, for NWP. Therefore, we have used ERS soil wetness measurements together with model surface soil moisture from the Global Soil Wetness Project 2 (GSWP2, Dirmeyer et al., 2006) simulations for the bias correction. The GSWP2 simulations are performed by forcing the UM off-line land surface model with observations based driving data (precipitation, short-wave and long-wave downward surface radiation, surface pressure, screen temperature, humidity and wind speed). Driving an off-line land surface model with NWP forcing data will not reproduce the NWP soil moisture climatology. The reason is that the NWP suite contains land data assimilation such as the soil moisture nudging scheme, soil temperature nudging scheme and snow analysis scheme. The land data assimilation corrects not only the random errors in the model but also persistent systematic errors in the model (see for example Drusch and Viterbo, 2007).

\section{Met Office numerical weather prediction system}

The Met Office uses the Unified Model (UM, Davies et al., 2005) for both numerical weather prediction and climate research. The version of the UM used in this work for the preoperational trials has a horizontal resolution of about $40 \mathrm{~km}$ with 70 (or 50) vertical levels for the atmosphere and is based on the version of the global UM which became operational for NWP in March 2010. The 4DVAR data assimilation scheme is used for the atmosphere (Rawlins et al., 2007) and an atmosphere analysis is produced every six hours.

\subsection{Representation of land surface processes}

The UM uses the MOSES 2 (Met Office Surface Exchange Scheme version 2) land surface scheme (Essery et al., 2001) and there is full and direct two way coupling between MOSES 2 and the atmosphere component of the UM. The soil is discretised into four layers of $0.1,0.25,0.65$ and $2 \mathrm{~m}$ thickness (from top to bottom). The soil hydrology is based on a finite difference form of the Richards equation and Darcy's law. The van Genuchten (1980) equations are used to describe the relationship of soil hydraulic conductivity and soil suction to the unfrozen volumetric soil moisture. The van Genuchten soil parameters depend on the soil texture (size distribution of the soil particles and the soil organic carbon content). The UM uses a new high resolution soil textures map that merges data from three separate sources; Harmonised World Soil Database (HWSD, FAO et al., 2008), State Soil Geographic Database (United States region, Miller and White, 1998) and point observations of soil sand, silt and clay fractions. The UM doesn't allow any vertical variation 
of soil texture, consequently data averaged over the $30 \mathrm{~cm}$ to $1 \mathrm{~m}$ depth of soil (subsoil) are used.

\subsection{UM T/q soil moisture nudging scheme}

The UM T/q soil moisture nudging scheme uses observations of screen temperature and humidity to analyse soil moisture (Best and Maisey, 2002). Because errors in the UM initial soil moisture field cause errors in forecasts of daytime screen temperature and humidity, knowledge of errors in forecasts of screen temperature and humidity can be used to slowly correct (nudge) the UM initial soil moisture. A reasonable simplification would be to state that the UM T/q soil moisture nudging scheme adjusts the model soil moisture to minimise the errors in six hour forecasts of daytime screen temperature and humidity. Errors in forecasts of screen temperature and humidity are due to many factors. Therefore, the UM T/q soil moisture nudging scheme seeks to identify and correct for those errors in screen temperature and humidity forecasts that are due to the model soil moisture. The UM T/q soil moisture nudging scheme is only active where there is evaporation, where the errors in screen temperature and humidity are of opposite sign (i.e. model boundary layer too warm and dry or model boundary layer too cold and moist), in unstable conditions (negative Richardson number) and where there is an absence of snow. The UM T/q soil moisture nudging only adjusts model soil moisture during daylight. Therefore, it is performed four times a day to update the whole globe. A significant advantage of the UM T/q soil moisture nudging scheme is that it can correct the model soil moisture not only for random errors but also for persistent systematic errors in the model (e.g. errors in model soil moisture due to persistent systematic errors in the model precipitation). A significant disadvantage of the UM T/q soil moisture nudging scheme is that the model soil moisture can become updated for model errors that are actually unrelated to soil moisture. The UM T/q soil moisture nudging scheme has been used operationally at the Met Office since 2005.

\section{Scatterometer data}

The advanced scatterometer (ASCAT) is an active C-band, $5.3 \mathrm{GHz}$ microwave sensor on board the polar-orbiting satellite METOP, launched during October 2006. ASCAT is the successor system to the ERS-1 (1991 to 1996) and ERS2 (launched 1996) C-band, $5.3 \mathrm{GHz}$ microwave scatterometers. ASCAT measures microwave backscatter with two sets of three antennas on each side of the satellite ground track. At each spatial point, a set of three antennas make three nearly co-located backscatter measurements at incidence angles ranging between 25 to $60^{\circ}$. ASCAT covers two swaths of $550 \mathrm{~km}$ width each separated by a gap of about $670 \mathrm{~km}$. Daily global coverage is $82 \%$ which is double that of the ERS-1/2 systems that use only one set of three antennas.
The ASCAT descending and ascending equator crossings occur at about 09:30 and 21:30 mean LST. Backscatter products are delivered at two horizontal resolutions For this study the higher resolution product provided by EUMETSAT, on a $12.5 \mathrm{~km}$ grid is used.

\subsection{Conversion of ASCAT backscatter measurements to surface soil wetness}

A time-series based, change detection algorithm (Wagner et al., 1999) is used to convert satellite backscatter measurements to a surface soil wetness $m_{\mathrm{s}}(t)$. It is assumed that the surface volumetric soil moisture is linearly related to $m_{\mathrm{s}}(t)$. First, a triplet of nearly co-located backscatter measurements are extrapolated to a reference angle of $40^{\circ}$ $\left(\sigma\left(40^{\circ}, t\right)\right)$ to eliminate any angular dependence. Soil roughness and topography are assumed to provide a time invariant contribution to $\sigma\left(40^{\circ}, t\right)$ while vegetation effects are assumed to vary seasonally. Therefore, the effects of soil roughness, topography and vegetation are removed by subtracting a dry reference function $\sigma_{\text {dry }}\left(40^{\circ}, t\right)$ that is annually periodic. $\sigma_{\mathrm{dry}}\left(40^{\circ}, t\right)$ is estimated at each spatial grid point from the lowest recorded values of $\sigma\left(40^{\circ}, t\right)$ in a long time series (at least $10 \mathrm{yr}$ long) of measurements from ERS-1/2. A wet reference value $\sigma_{\text {wet }}\left(40^{\circ}\right)$ that is time invariant, is estimated at each spatial grid point from the highest recorded value of $\sigma\left(40^{\circ}, t\right)$ in a long time-series of measurements. Thus the conversion of $\sigma\left(40^{\circ}, t\right)$ to $m_{\mathrm{s}}(t)$ is given by:

$m_{\mathrm{s}}(t)=\frac{\sigma\left(40^{\circ}, t\right)-\sigma_{\mathrm{dry}}\left(40^{\circ}, t\right)}{\sigma_{\mathrm{wet}}\left(40^{\circ}\right)-\sigma_{\mathrm{dry}}\left(40^{\circ}, t\right)}$.

\subsection{Comparison of ERS/ASCAT soil moisture products with ground based soil moisture observations}

Albergel et al. (2009), Rudiger et al. (2009), Naeimi et al. (2009) and Scipal (2002) have found good agreement between ERS or ASCAT derived soil moisture and ground based soil moisture observations. Albergel et al. (2009) compare ASCAT soil wetness with in-situ observations for South-Western France. Albergel et al. (2009) find that ASCAT observations are well correlated with the in-situ data ( $r \simeq 0.56$ ) and no systematic dry or wet bias is observed. Naeimi et al. (2009) compare the ERS scatterometer derived soil wetness with in-situ measurements at $5 \mathrm{~cm}$ from the Oklahoma Mesonet, for the three year period (2004-2006) and find high correlations between the derived soil wetness and in-situ measurements. Naeimi et al. (2009) also find high correlation between the scatterometer derived soil wetness and ECMWF ERA-Interim reanalysis surface soil moisture data. Scipal (2002) has compared ERS derived volumetric soil moisture with in-situ observations from China, Russia, Ukraine, Illinois and India. Scipal (2002) finds that the ERS derived volumetric soil moisture has an accuracy of between $0.05 \mathrm{~m}^{3} \mathrm{~m}^{-3}$ to $0.07 \mathrm{~m}^{3} \mathrm{~m}^{-3}$. 

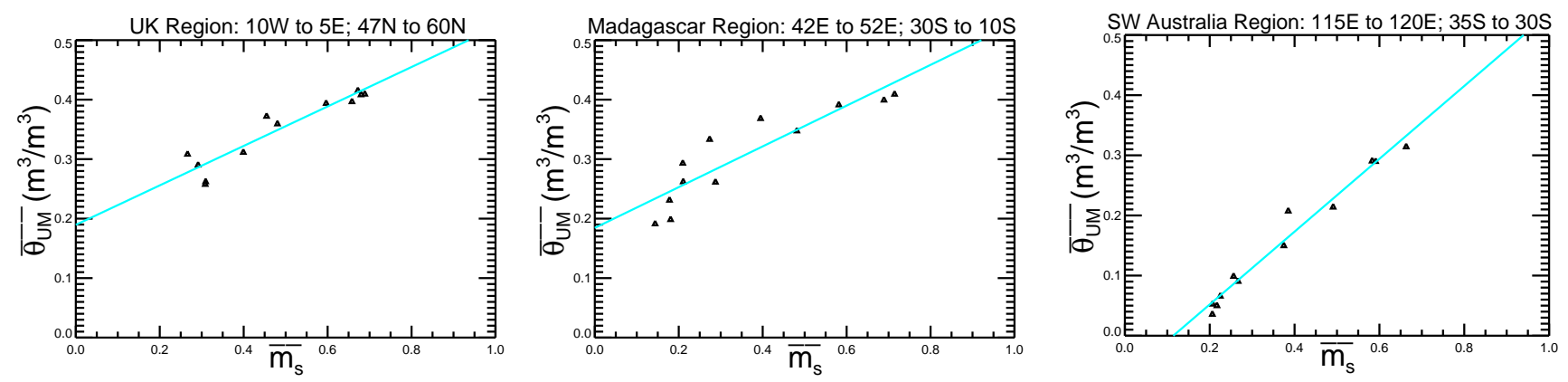

Fig. 2. Plots of UM level 1 volumetric soil moisture monthly climatology $\overline{\theta_{\mathrm{UM}}}$ vs. the ASCAT surface soil wetness monthly climatology $\overline{m_{\mathrm{S}}}$ for the $\mathrm{UK}$ region $\left(10^{\circ} \mathrm{W}\right.$ to $5^{\circ} \mathrm{E} ; 47^{\circ} \mathrm{N}$ to $\left.60^{\circ} \mathrm{N}\right)$, Madagascar region $\left(42^{\circ} \mathrm{E}\right.$ to $52^{\circ} \mathrm{E} ; 30^{\circ} \mathrm{S}$ to $\left.10^{\circ} \mathrm{S}\right)$ and $\mathrm{SW}$ Australia region. $\left(115^{\circ} \mathrm{E}\right.$ to $120^{\circ} \mathrm{E} ; 35^{\circ} \mathrm{S}$ to $30^{\circ} \mathrm{S}$ ). Each plot contains 12 data points, one data point for each month of the year.

\section{Conversion of surface soil wetness to surface volumetric soil moisture}

Before the ASCAT surface soil wetness $\left(m_{\mathrm{s}}\right)$ can be assimilated, it must be converted to surface volumetric soil moisture $\left(\theta_{\text {scat }}\right)$ and bias corrected. Following Scipal et al. (2008a) a linear relationship is assumed,

$\theta_{\text {scat }}(t)=a+b \times m_{\mathrm{s}}(t)$,

where $a$ and $b$ are spatially varying, time invariant, matching parameters. At each UM land point, $a$ is related to the local minimum occurring value of the model surface soil moisture while $b$ is related to the local dynamic range of the model surface soil moisture. From Eq. (2), the monthly climatology of the ASCAT surface volumetric soil moisture is given by:

$\overline{\theta_{\text {scat }}(t)}=a+b \times \overline{m_{\mathrm{s}}(t)}$,

where $\overline{m_{\mathrm{S}}(t)}$ is the monthly climatology of ERS surface soil wetness. $\overline{m_{\mathrm{S}}(t)}$ is derived from a long time-period ${ }^{1}$ of ERS backscatter data and is provided by the ASCAT level 2 soil wetness BUFR (Binary Universal Form for the Representation of meteorological data) product. In an analogous manner to CDF matching, we impose the condition that

$\overline{\theta_{\text {scat }}(t)}=\overline{\theta_{\mathrm{UM}}(t)}$,

where $\overline{\theta_{\mathrm{UM}}(t)}$ is the climatology of UM level 1 volumetric soil moisture that is derived by driving the UM off-line land surface model with observation based driving data provided by GSWP2 (Dirmeyer et al., 2006) that covers the period January 1986 to December 1995 at a spatial resolution of $1^{\circ}$ latitude/longitude. The parameters and parameterisations used by the off-line GSWP2 simulations, including van Genuchten soil hydraulics, are similar to those used by the UM NWP suite.

\footnotetext{
${ }^{1}$ The years 1991 to 2001 with a limited amount of data from 2003 to 2007 (Bartalis, 2009).
}

Combining Eqs. (2)-(4) then gives the equation used to convert ASCAT surface soil wetness to volumetric soil moisture:

$\theta_{\mathrm{scat}}(t)=\overline{\theta_{\mathrm{UM}}(t)}+b \times\left(m_{\mathrm{S}}(t)-\overline{m_{\mathrm{S}}(t)}\right)$.

From Eqs. (3) and (4), the parameter $b$ can be estimated from the slope of the line of best fit through a scatter plot of $\overline{\theta_{\mathrm{UM}}(t)}$ against $\overline{m_{\mathrm{s}}(t)}$. Figure 2 shows example scatter plots with lines of best fit for three different regions. Since $\overline{\theta_{\mathrm{UM}}(t)}$ and $\overline{m_{\mathrm{s}}(t)}$ are monthly climatologies, there are twelve data points on each plot of Fig. 2, one for each month. The scatter plots indicate that for regions with significant vegetation cover (such as the UK and Madagascar) the slope of the line of best fit is shallower and $b \simeq\left(\theta_{\mathrm{s}}-\theta_{\mathrm{w}}\right)$ while for regions with significant amounts of bare soil (such as SW Australia) the slope of the line of best fit is steeper and $b \simeq \theta_{\mathrm{s}}$. The use of scatter plots to derive the $b$ parameter only works where the surface soil moisture has a distinct seasonal cycle and where the soil is unfrozen for most of the year. Therefore, instead, we assume

$b=\left(\theta_{\mathrm{s}}-v \theta_{\mathrm{W}}\right)$,

where $\theta_{\mathrm{s}}$ is the volumetric soil moisture at saturation, $\theta_{\mathrm{w}}$ is the volumetric soil moisture at the wilting point and $v$ is the fraction of vegetation cover. Thus the $b$ parameter is determined using UM soil texture and vegetation cover data. The $b$ parameter is time invariant and has the same horizontal resolution as the UM. The UM vegetation fractions are derived from the International Geosphere Biosphere Programme (IGBP) global land cover dataset. The choice of $b$ in Eq. (6) is similar to that used by Scipal (2002) and Ceballos et al. (2005) who use $b=\left(0.5 \theta_{\mathrm{s}}+0.5 \theta_{\mathrm{fc}}-\theta_{\mathrm{w}}\right)$, where $\theta_{\mathrm{fc}}$ is the volumetric soil moisture at field capacity. The use of Eq. (6) gives larger values for $b$ which is justified since we are considering surface soil moisture while Scipal (2002) and Ceballos et al. (2005) consider root zone soil moisture.

Figure 3 compares histograms of the distribution of ASCAT surface soil wetness $m_{\mathrm{s}}$ with the distribution of UM 

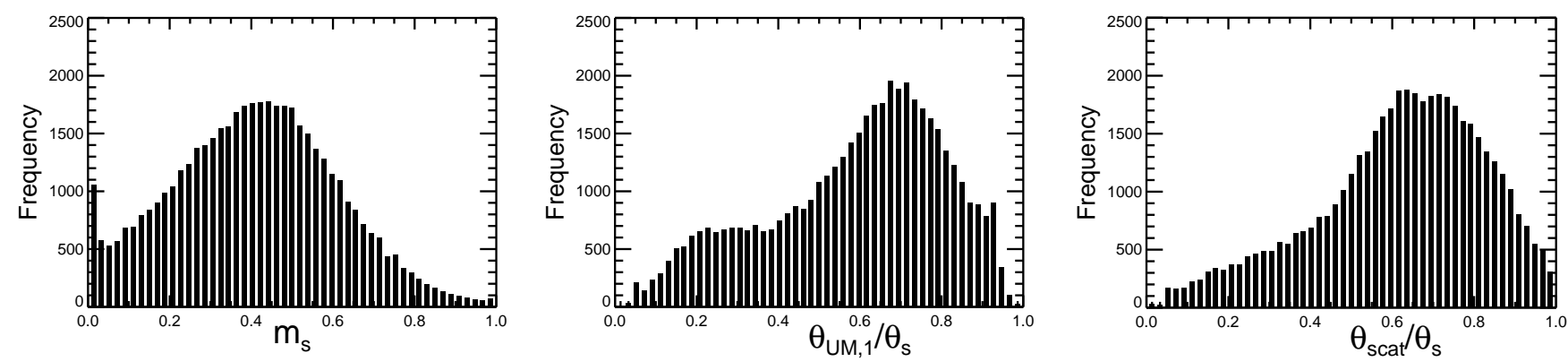

Fig. 3. Histograms of ASCAT surface soil wetness $m_{\mathrm{s}}$, UM level 1 soil wetness $\theta_{\mathrm{UM}, 1} / \theta_{\mathrm{s}}$ and converted ASCAT soil wetness $\theta_{\mathrm{scat}} / \theta_{\mathrm{s}}$. Data is for the NW Europe region, $15^{\circ} \mathrm{W}$ to $15^{\circ} \mathrm{E} ; 37^{\circ} \mathrm{N}$ to $60^{\circ} \mathrm{N}$ and time period May to July 2009.

level 1 soil wetness $\theta_{\mathrm{UM}, 1} / \theta_{\mathrm{S}}$ for the NW Europe region $\left(\theta_{\mathrm{UM}, 1}\right.$ is output from the UM T/q soil moisture nudging scheme of a Control experiment). The shapes of the $m_{\mathrm{s}}$ and $\theta_{\mathrm{UM}, 1} / \theta_{\mathrm{S}}$ distributions are significantly different. Also shown is the histogram of the distribution of converted ASCAT soil wetness $\theta_{\text {scat }} / \theta_{\mathrm{s}}$. The histogram for $\theta_{\mathrm{UM}, 1} / \theta_{\mathrm{S}}$ is similar to the histogram for $\theta_{\text {scat }} / \theta_{\mathrm{s}}$, although the histogram for $\theta_{\mathrm{UM}, 1} / \theta_{\mathrm{s}}$ contains a small second mode which is not present in the histogram for $\theta_{\text {scat }} / \theta_{\mathrm{s}}$. The model soil wetness is calculated as a fraction of saturation because the UM surface soil moisture has a large dynamic range and can fall significantly below the wilting point or rise significantly above the field capacity. Figure 3 can be compared with Figs. 5 and 7 of Mahfouf (2010) who also defines model surface soil wetness as a fraction of saturation.

Note that we are not using CDF matching. The reason is that van Genuchten soil hydraulics was only introduced into the operational global UM during March 2010 and its introduction has a significant impact on the global UM soil moisture climatology. Consequently, we don't have a long enough period of model soil moisture data for the CDF matching. However, the constraint that $\overline{\theta_{\text {scat }}(t)}=\overline{\theta_{\mathrm{UM}}(t)}$ ensures that $\theta_{\text {scat }}(t)$ will be consistent with the assumptions made by the UM land surface model and unbiased in a similar sense to CDF matching (CDF matching, in addition, allows the constraint of higher order moments such as variance, skewness and kurtosis).

\section{Quality control of the ASCAT data}

A quality control (QC) step is implemented to deal with missing data and to filter out measurements from regions with sea, snow cover, frost, mountains, dense vegetation, sand dunes, wetlands and open water. There is also a facility to reject data based on cross-track cell number. Once the ASCAT surface soil wetness measurements $m_{\mathrm{S}}$ have been converted to surface volumetric soil moisture $\theta_{\text {scat }}$, a background quality control check is performed. If an observation is rejected by one $\mathrm{QC}$ check it is not tested by any other QC check, the QC checks are performed in the following order:

Snow. ASCAT data is rejected where the UM snow analysis (Pullen et al., 2010) indicates snow amounts greater than $0.05 \mathrm{~kg} \mathrm{~m}^{-2}$.

Frost. ASCAT data is rejected where the UM screen temperature analysis has temperatures below $275.15 \mathrm{~K}$.

Wetlands. ASCAT data is rejected where the inundation and wetland amount has a value greater than $15 \%$. The inundation and wetland amount is provided by the ASCAT level 2 soil wetness BUFR product (Bartalis et al., 2008)..

Mountains. ASCAT data is rejected where the topographic complexity has a value greater than $20 \%$. The topographic complexity is derived from the US Geological Survey GTOPO30 global digital elevation data. The topographic complexity is provided by the ASCAT level 2 soil wetness BUFR product.

ASCAT estimated error. ASCAT data is rejected where the error in the ASCAT surface soil wetness is estimated to be greater than $7 \%$. This check rejects ASCAT data from regions with dense vegetation (e.g. the Amazon) and sand dunes. The estimated error is provided by the ASCAT level 2 soil wetness BUFR product. The ASCAT estimated error is rather too optimistic so a low value for the QC threshold is appropriate.

Cross track cell number. Figure 4 shows the error in the ASCAT surface soil wetness as a function of cross track cell number. To generate the figures, ASCAT data is extracted for a 3 day period, quality controlled and re-gridded onto a grid with $\simeq 25 \mathrm{~km}$ horizontal spacing. The root mean square difference between the quality controlled ASCAT measurements and the re-gridded data is then calculated for each cross track cell. Based on Fig. 4, ASCAT data is rejected for cells 1 to 4,40 to 43 and 79 to 82 .

Background quality control check. The background quality control check is performed after the ASCAT surface soil wetness measurements have been converted to volumetric 
soil moisture. For the quality control, we assume that the observation error $\sigma_{\mathrm{o}}=0.07 \mathrm{~m}^{3} \mathrm{~m}^{-3}$, the background error $\sigma_{\mathrm{b}}=0.07 \mathrm{~m}^{3} \mathrm{~m}^{-3}$, the prior probability of gross error $p(G)=0.05$ and the observation is rejected if the posterior probability of gross error $p(G \mid o)>0.5$. Following Lorenc and Hammon (1988),

$$
p(G \mid o)=\frac{p(o \mid G) p(G)}{p(o)}=\frac{\kappa p(G)}{\kappa p(G)+N\left(y, \sigma^{2}\right)(1-p(G))}
$$

where $\kappa=1 / \theta_{\mathrm{s}}, y=\theta_{\mathrm{scat}}-\theta_{\mathrm{ib}, 1}, \sigma^{2}=\sigma_{\mathrm{o}}^{2}+\sigma_{\mathrm{b}}^{2}$ and

$N\left(y, \sigma^{2}\right)=\frac{1}{\sqrt{2 \pi \sigma^{2}}} \exp \left(\frac{-y^{2}}{2 \sigma^{2}}\right)$.

$\theta_{\mathrm{ib}, 1}$ is the $\mathrm{UM}$ intermediate soil moisture background for soil level 1. $\theta_{\mathrm{ib}, 1}$ is calculated by the UM T/q soil moisture nudging scheme.

The specified values of $\sigma_{o}$ and $\sigma_{b}$ are quite large and this will result in fewer ASCAT observations rejected by the background quality control check. The assumption that $\sigma_{o}=\sigma_{b}=0.07 \mathrm{~m}^{3} \mathrm{~m}^{-3}$ means that an ASCAT observation is rejected if $|y|>0.26 \mathrm{~m}^{3} \mathrm{~m}^{-3}$. For example, an alternative assumption that $\sigma_{o}=\sigma_{b}=0.05 \mathrm{~m}^{3} \mathrm{~m}^{-3}$ would mean that an ASCAT observation is rejected if $|y|>0.20 \mathrm{~m}^{3} \mathrm{~m}^{-3}$.

\section{Assimilation of ASCAT derived soil moisture}

The ASCAT surface volumetric soil moisture values $\theta_{\text {scat }}$ that have passed all the QC checks are gridded onto the UM grid. No thinning is performed, instead super-obing is used. Since the ASCAT data has a higher spatial resolution than the model $(12.5 \mathrm{~km}$ vs $40 \mathrm{~km})$, a model grid square can contain several $\theta_{\text {scat }}$ values in any six hour time period. The super-ob value $\tilde{\theta}_{\text {scat }}$ is the arithmetic mean of all $\theta_{\text {scat }}$ values that fall within the same model grid square in a six hour time period.

A simple nudging scheme is used to nudge the UM level 1 volumetric soil moisture (output by the UM T/q soil moisture nudging scheme) $\theta_{\mathrm{ib}, 1}$ towards the ASCAT derived super-ob value $\tilde{\theta}_{\text {scat }}$. Such a scheme is computationally very cheap. The soil moisture analysis is given by

$\theta_{a, l}=\left\{\begin{array}{cc}\theta_{\mathrm{ib}, 1}+K\left(\tilde{\theta}_{\mathrm{scat}}-\theta_{\mathrm{ib}, 1}\right) & l=1 \\ \theta_{\mathrm{ib}, l} & l>1\end{array}\right.$,

where $l$ is the model soil level. The assimilation time window is six hours long and the soil moisture analysis is performed four times a day. See Fig. 1 for a schematic overview of the soil moisture analysis scheme. Brocca et al. (2010b) applied a similar ASCAT nudging scheme to improve the prediction of runoff from a land surface model.

$K$ is a constant scalar value that is user specified and doesn't vary spatially or temporally. The trials described in this paper assume $K=0.2$. This value was chosen so that the root mean square (RMS) size of ASCAT nudges is about
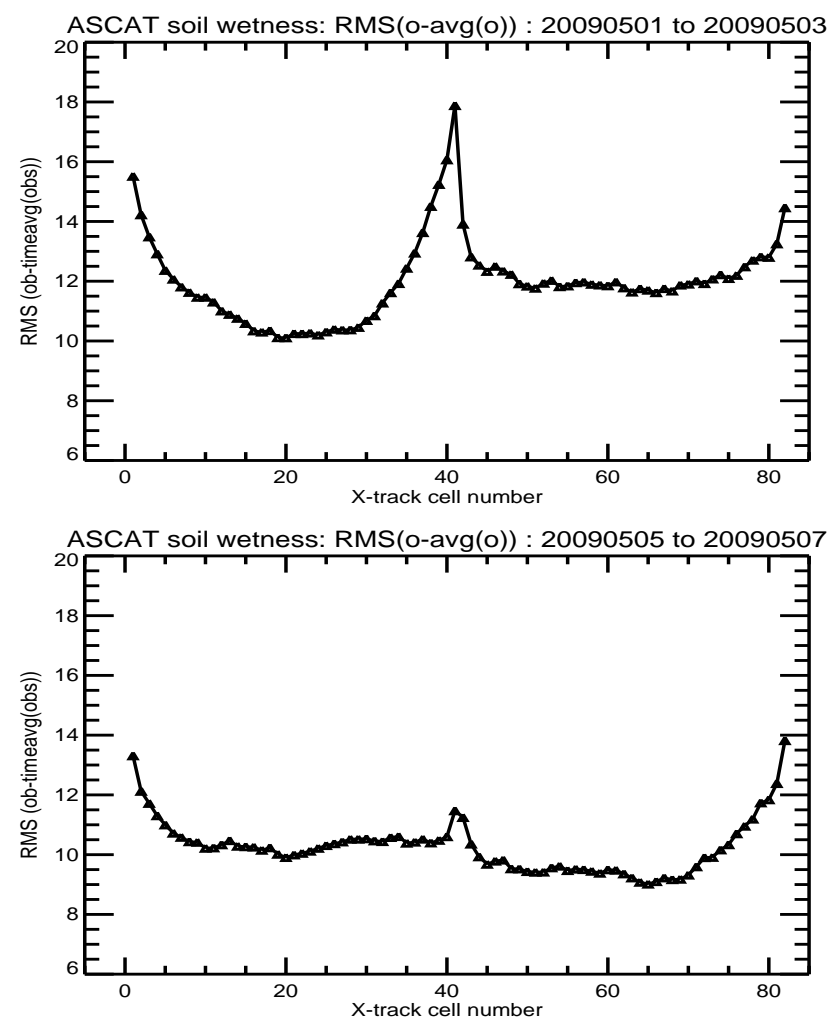

Fig. 4. Error in ASCAT surface soil wetness measurements as a function of cross track cell number. The upper panel shows errors for the 3 day period; 1 May 2009 to 3 May 2009. On 4 May 2009, EUMETSAT implemented an operational improvement to the ASCAT backscatter bias correction. The lower panel shows errors for the 3 day period; 5 May 2009 to 7 May 2009. The benefit of the improved bias correction by EUMETSAT is clearly visible in the lower panel, showing significantly smaller errors.

$1 \mathrm{~mm} \mathrm{day}^{-1}$. The amount of water added per day by the ASCAT nudging scheme can be calculated as:

water added $=0.82 \times \rho_{w} d_{1} K\left(\tilde{\theta}_{\mathrm{scat}}-\theta_{\mathrm{ib}, 1}\right)$

where 0.82 is the ASCAT daily global coverage, $\rho_{w}=$ $1000 \mathrm{~kg} \mathrm{~m}^{-3}$ is the density of water and $d_{1}=0.1 \mathrm{~m}$ is the thickness of $\mathrm{UM}$ soil layer 1 . Assuming that $\operatorname{RMS}\left(\tilde{\theta}_{\text {scat }}-\theta_{i b, 1}\right) \simeq 0.06 \mathrm{~m}^{3} \mathrm{~m}^{-3}$ then provides the estimate that $\operatorname{RMS}($ water added $) \simeq 1 \mathrm{~mm} \mathrm{day}^{-1}$.

\section{Trials of ASCAT soil wetness assimilation}

The soil moisture analysis scheme described in this paper is computationally very cheap. However, testing will be computationally very expensive. The reason is that there will be feedbacks between the soil moisture analysis, the land surface model, the atmosphere model and the 4DVAR atmosphere data assimilation. Therefore, for comprehensive testing, the full Global UM NWP suite must be run. 


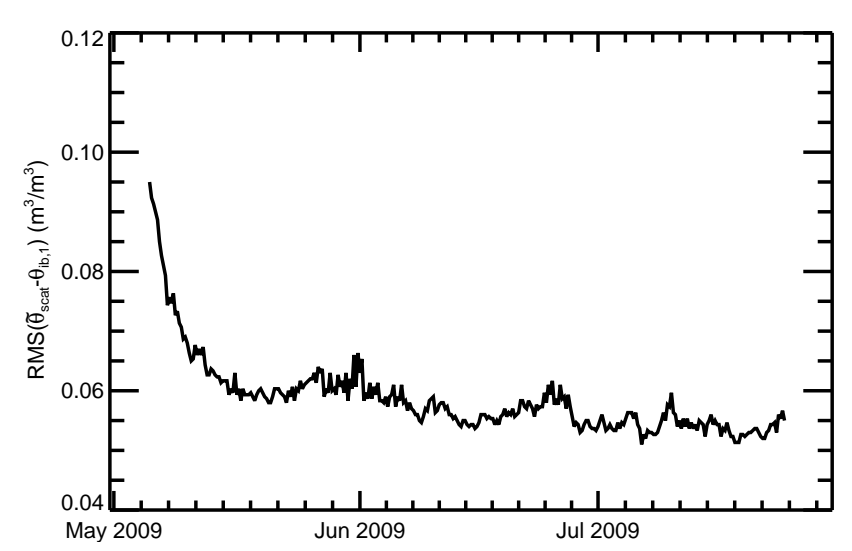

Fig. 5. Time series of RMS differences between $\tilde{\theta}_{\text {scat }}$ and the UM level 1 volumetric soil moisture $\theta_{\mathrm{ib}, 1}$, from the Test experiment of trial 1 . The statistics are calculated every six hours and the domain is the varying region covered by the ASCAT measurements during a six hour period.

Other researchers testing soil moisture analysis schemes in a NWP context have run trials which are typically one to three months long and cover the northern hemisphere Spring/Summer time period (e.g. Draper et al., 2011; Mahfouf, 2010; Scipal et al., 2008a; Drusch, 2007).

Listed below are the trials whose results are described in this paper.

\begin{tabular}{llccc}
\hline Trial Period & $\begin{array}{c}\text { Trial } \\
\text { length } \\
\text { (days) }\end{array}$ & $\begin{array}{c}\text { UM } \\
\text { vertical } \\
\text { levels }\end{array}$ & $K$ \\
\hline Trial 1 & May to Jul 2009 & 79 & 70 & 0.2 \\
Trial 2 & Aug to Sep 2009 & 38 & 50 & 0.2 \\
\hline
\end{tabular}

Each trial consists of two experiments using the global NWP suite; a Control experiment and a Test experiment. The Control uses the T/q soil moisture nudging to analyse soil moisture. The Test uses both the T/q soil moisture nudging and the ASCAT nudging scheme running sequentially to analyse soil moisture (see Fig. 1). Otherwise the Control and Test of each trial are identical. For the longer trial 1, the UM six day forecasts start at $12 \mathrm{Z}$ each day, for the shorter trial 2, UM six day forecasts start from both $00 \mathrm{Z}$ and $12 \mathrm{Z}$ each day. Because trialling is computationally very expensive and takes a long time, we first ran some short, typically one month long, trials to check that the ASCAT nudging scheme works correctly. The short trials as well some quality control statistics are described in a technical report (Dharssi et al., 2010).

\subsection{ASCAT minus UM background statistics}

Figure 5 shows that the land surface model is able to retain the information from the ASCAT soil wetness assimilation. Within a few weeks, the UM level 1 soil moisture $\theta_{\mathrm{ib}, 1}$ adjusts towards the ASCAT values $\tilde{\theta}_{\text {scat }}$, such that the RMS values level off at about $0.05 \mathrm{~m}^{3} \mathrm{~m}^{-3}$. This value is very similar to the expected accuracy of the ASCAT volumetric soil moisture. Figure 5 shows results from trial 1, the other trials also show similar results.

\subsection{Soil moisture nudges}

Figure 6 shows the RMS and mean size of soil moisture nudges $\left(\mathrm{mm} \mathrm{day}^{-1}\right)$ from trial 1 for the July 2009 period. The RMS size of soil moisture nudges by both schemes is similar in trial 1.

It may seem inconsistent to compare UM T/q soil moisture nudges in the top $1 \mathrm{~m}$ of soil with ASCAT nudges in the top $10 \mathrm{~cm}$ of soil, at first sight. However, the UM T/q scheme adds water throughout the plant root zone and generally only adds a small amount of water to the top $10 \mathrm{~cm}$ of soil. Consequently, only comparing water added to the top $10 \mathrm{~cm}$ of soil would give the misleading impression that ASCAT nudges are much bigger than UM T/q soil moisture nudges. The ASCAT nudges in the top $1 \mathrm{~m}$ of soil are equal to the ASCAT nudges in the top $10 \mathrm{~cm}$ of soil. Therefore, there is no inconsistency in comparing ASCAT nudges in the top $10 \mathrm{~cm}$ of soil with UM T/q soil moisture nudges in the top $1 \mathrm{~m}$ of soil.

The mean size of soil moisture nudges $\left(\mathrm{mm} \mathrm{day}^{-1}\right)$ from trial 1 for the July 2009 period show that in the Northern Hemisphere middle-latitude regions there is a general moistening of the soil by the UM T/q soil moisture nudging scheme. The ASCAT nudges do show a different pattern, in particular for the Western United States (US) where the ASCAT nudging dries the soil. Draper et al. (2011) also find that nudges due to satellite derived soil moisture measurements can often be of different sign to the nudges due to the screen observations. This might indicate that the model surface and sub-surface soil moisture have errors with opposite sign. Or it may indicate that the T/q soil moisture nudging is correcting for model errors that are unrelated to soil moisture. Such conflicting updates will tend to increase the vertical gradient of the model soil moisture. However, this doesn't appear to cause any problems. Observed soil moisture profiles often show significant vertical gradients and the model appears to under-estimate the vertical gradient of soil moisture.

Figure 7 shows the average difference in volumetric soil moisture $\left(\mathrm{m}^{3} \mathrm{~m}^{-3}\right)$ between the Test and Control experiments of trial 1 for the July 2009 period. The differences are biggest for soil level 1 and become progressively smaller for the deeper soil levels. For trial 1, ASCAT nudging moistens the soil over much of the Southern Hemisphere, tropics and Eastern US. ASCAT nudging dries the soil over much of North Africa, Western US and Central Asia. ASCAT nudging has little impact on soil moisture for the European region. 

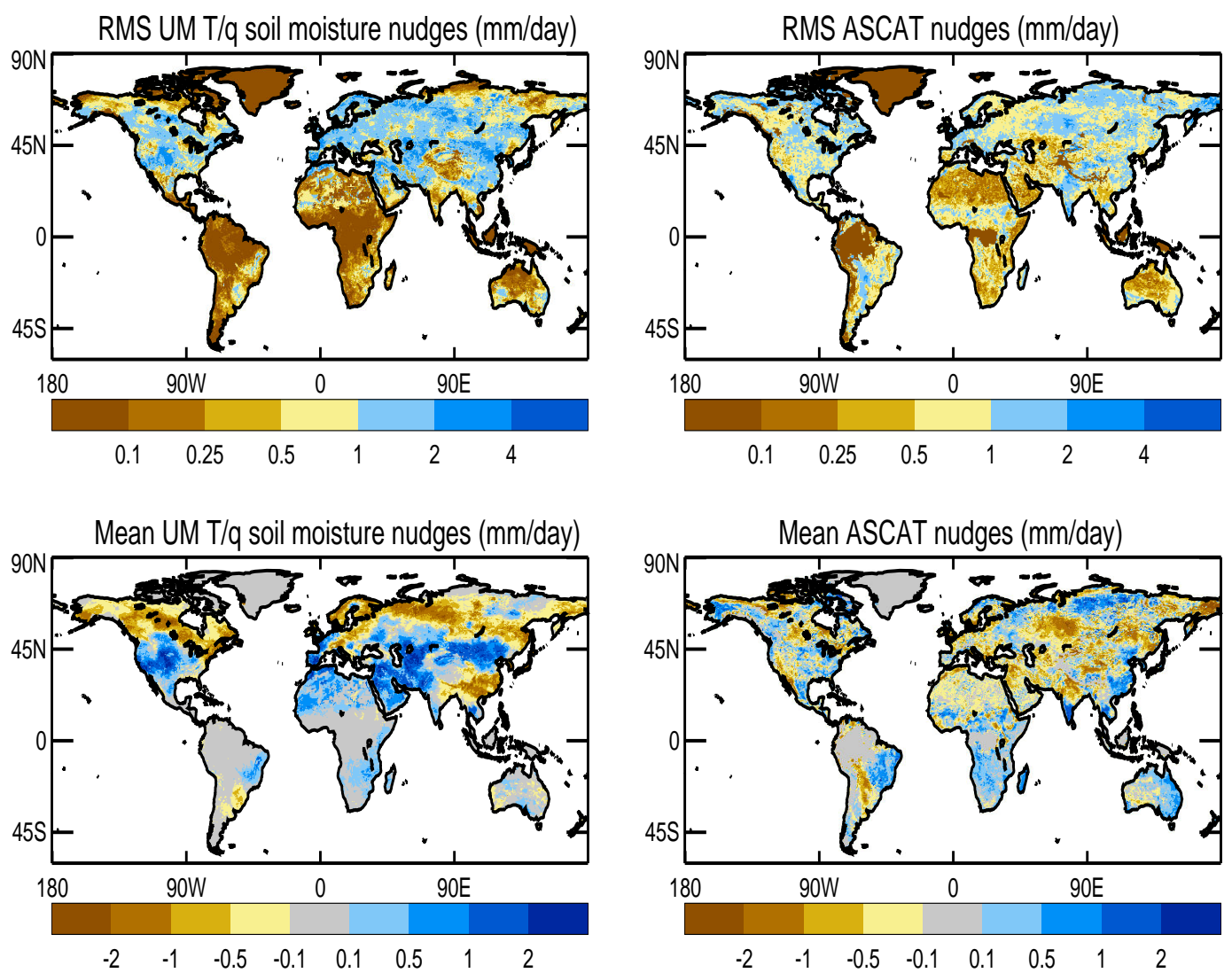

Fig. 6. RMS (top panels) and mean (lower panels) size of soil moisture nudges (mm day ${ }^{-1}$ ) from trial 1 for the July 2009 period. The left panels shows nudges in the top $1 \mathrm{~m}$ of soil by the UM T/q soil moisture nudging scheme in the Control experiment. The right panels shows nudges in the topmost UM soil level by the ASCAT nudging in the Test experiment.

\subsection{Impact of assimilating ASCAT soil wetness on forecasts of screen temperature and humidity}

Soil moisture influences the partitioning of net surface radiation into sensible, latent and ground heat fluxes. Consequently, soil moisture can have a significant impact on forecasts of screen temperature and humidity. Figures 8 and 9 show verification of UM screen temperature and screen relative humidity forecasts against observations for trial 1 , which covers the May to July 2009 time period. These figures shows that ASCAT soil wetness assimilation has a positive impact in the tropics and Australia. For Europe (results not shown), North America and the Northern Hemisphere the impact is neutral. Mahfouf (2010) has assimilated ASCAT derived soil moisture using a simplified Extended Kalman Filter into a limited area NWP model covering Western Europe and finds a broadly neutral impact on forecasts.

Trial 1 (Figs. 8 and 9) show a diurnal variation in forecast skill. Such a diurnal variation should be expected. Soil moisture affects transpiration from plants and transpiration is strongly linked to photosynthesis. Therefore, errors due to soil moisture are expected to be larger during the day and smaller at night. For north America, errors are larger at $0 \mathrm{Z}$ than at $12 \mathrm{Z}$. While for Europe the errors are larger at $12 \mathrm{Z}$ than at $0 Z$. The diurnal variation in forecast skill can also be due to other sources such as errors in model clouds and surface albedo.

Figure 10 shows screen verification results for trial 2. Trial 2 starts forecasts from both $00 \mathrm{Z}$ and $12 \mathrm{Z}$ as compared to trial 1 where forecasts are only started from $12 Z$. This is the reason that trial 2 screen verification doesn't show the diurnal variation in forecast skill seen in the trial 1 screen verification. Again ASCAT soil wetness assimilation gives a positive impact in the tropics and Australia. This time, there is also a positive impact for North America and the Northern Hemisphere. Again, for Europe the impact is neutral.

The land surface has a much longer memory than the atmosphere and so improvements to the soil moisture analysis often show bigger improvements at the longer forecast times (Figs. 8, 9 and 10). Errors in screen temperature and humidity are small at the start of a UM forecast since the 4DVAR atmosphere data assimilation scheme assimilates screen level temperature and humidity observations. 

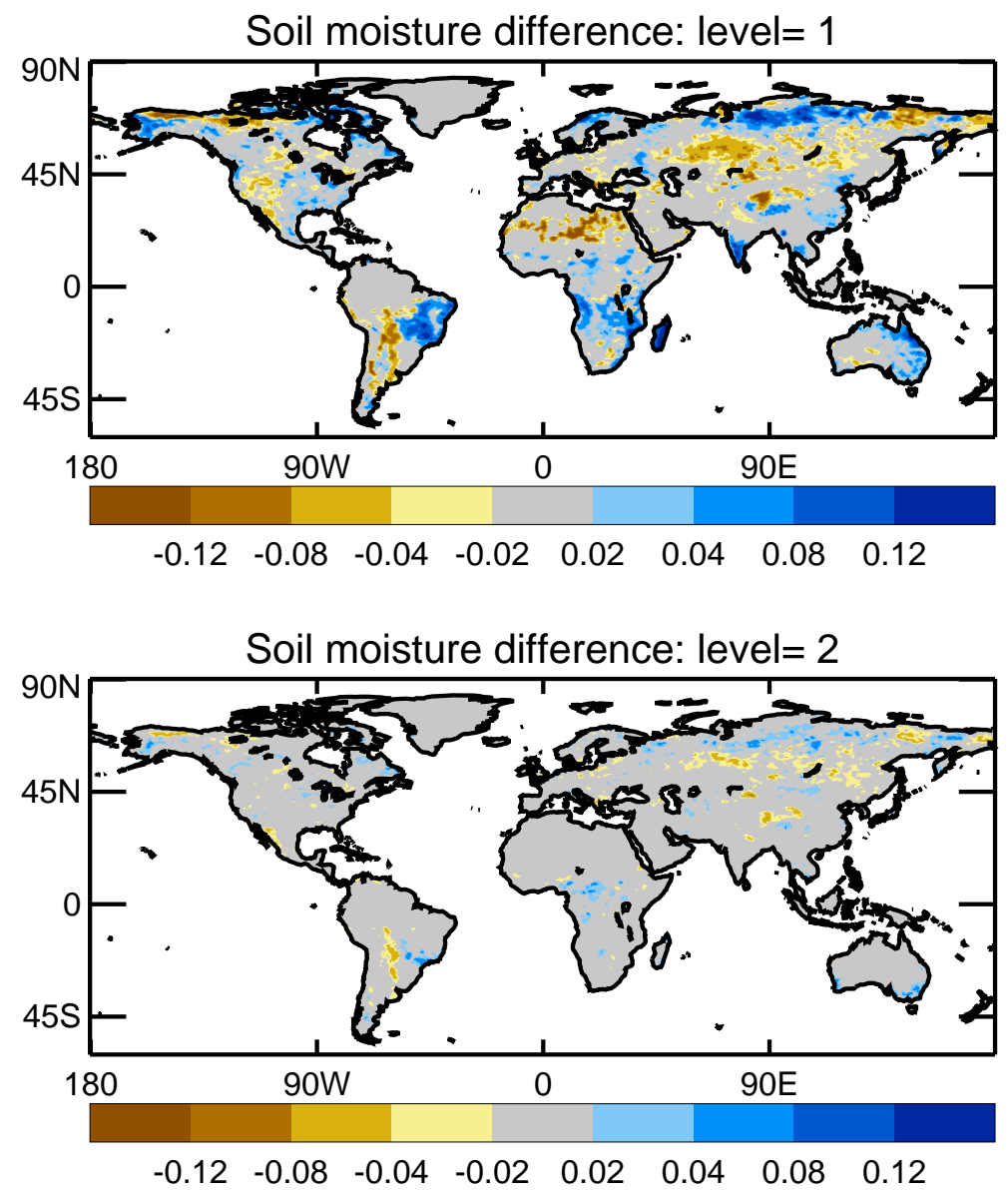

Fig. 7. Trial 1, Test minus Control differences in volumetric soil moisture $\left(\mathrm{m}^{3} \mathrm{~m}^{-3}\right)$ for the July 2009 period. The top panel shows differences for the topmost UM soil level, the lower panel shows differences for UM soil level 2.

Koster et al. (2006) suggest that both the north America and Tropics regions contain hot-spots of high landatmosphere coupling. This may be the reason for a positive benefit of ASCAT assimilation in those regions. Bigger improvements from ASCAT soil wetness assimilation are expected in those regions where screen level temperature and humidity observations are sparse. Many areas of the tropics have sparse screen observation coverage and this would also explain the good results seen in the tropics. The sparse screen observation coverage in the interior of Australia might explain the good results from ASCAT soil wetness assimilation found for Australia. Europe has very dense screen observation coverage and this most likely explains the neutral impact from ASCAT soil wetness assimilation for Europe.

\section{Comparison of model with in-situ soil moisture measurements}

The US Department of Agriculture, Soil Climate Analysis Network (USDA SCAN) is a sparse network that consists of about 100 automated sites, spread over the US that take soil moisture measurements hourly at soil depths of $5 \mathrm{~cm}$, $10 \mathrm{~cm}, 20 \mathrm{~cm}, 50 \mathrm{~cm}$ and $100 \mathrm{~cm}$. USDA SCAN sites use Stevens vitel hydra probes that measure the dielectric constant of the soil to determine soil moisture (Seyfried and Murdock, 2004; Seyfried et al., 2005). According to the user manual, the probes have an accuracy of $0.03 \mathrm{~m}^{3} \mathrm{~m}^{-3}$. Since these are point observations (and we are interested in the grid square average) they also contain errors of representativity. According to Famiglietti et al. (2008) the error of representativeness depends on the length scale of interest. "Results showed that variability generally increases with extent scale. The standard deviation increased from $0.036 \mathrm{~cm}^{3} \mathrm{~cm}^{-3}$ at the $2.5 \mathrm{~m}$ scale to $0.071 \mathrm{~cm}^{3} \mathrm{~cm}^{-3}$ at the $50 \mathrm{~km}$ scale." In this study, the UM has a horizontal resolution of about $40 \mathrm{~km}$ and therefore an error of representativity of $0.06 \mathrm{~m}^{3} \mathrm{~m}^{-3}$ in the USDA SCAN observations is assumed. This error of representativity value is consistent with Miralles et al. (2010) who consider smaller spatial scales ranging from $12 \mathrm{~km}$ to $25 \mathrm{~km}$ and Loew and Schlenz (2011). Since USDA SCAN is a sparse network, it is not possible to use spatial averaging to reduce the error of representativity in the USDA SCAN 

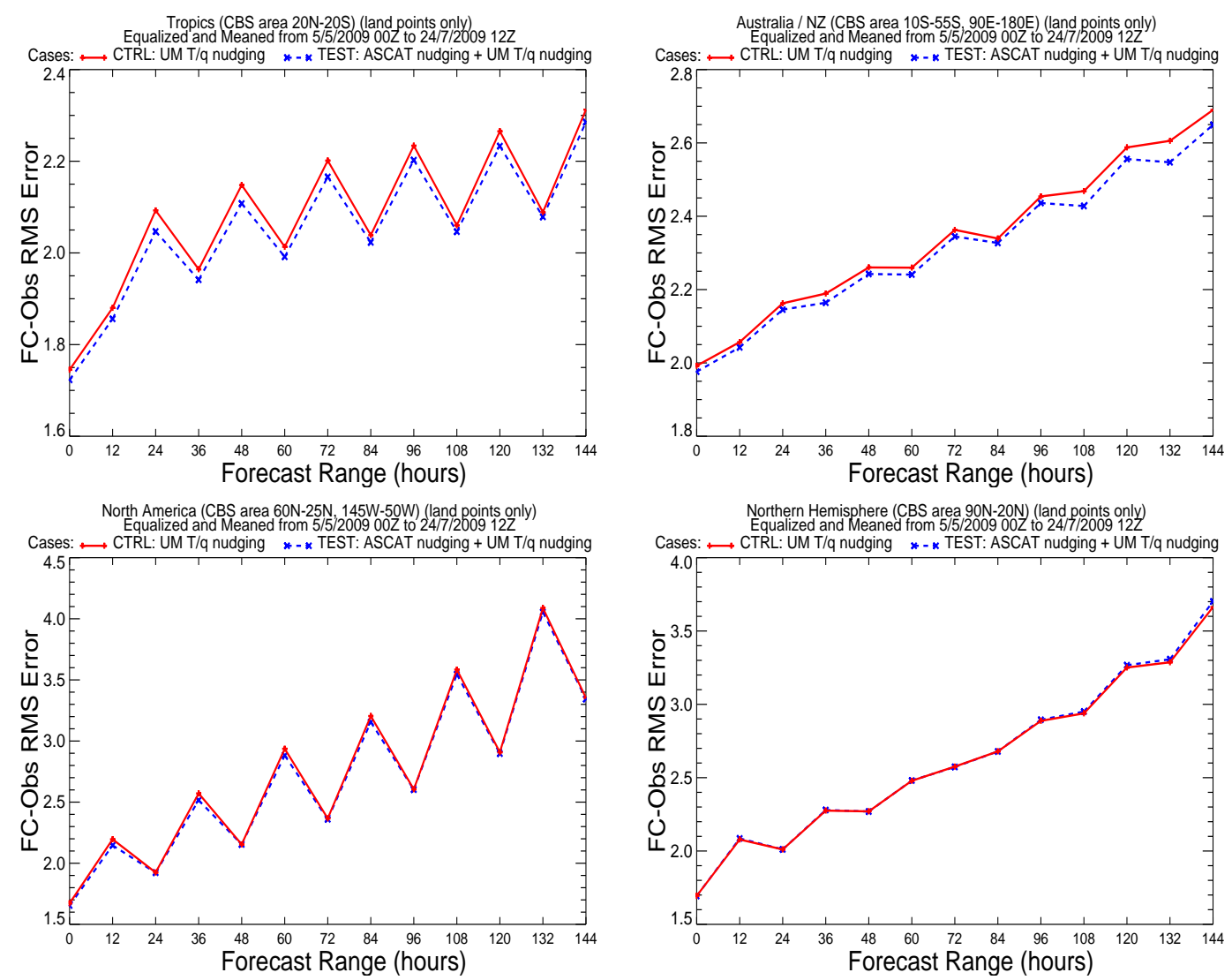

Fig. 8. Trial 1 verification of UM screen temperature forecasts against observations for land points only and the time period 5 May 2009 to 24 July 2009. The solid red lines (dashed blue lines) show RMS differences for the Control experiment (Test experiment that also assimilates ASCAT surface soil wetness measurements). Results are shown for the tropics $\left(20^{\circ} \mathrm{S}\right.$ to $\left.20^{\circ} \mathrm{N}\right)$, Australia $\left(55^{\circ} \mathrm{S}\right.$ to $10^{\circ} \mathrm{S}, 90^{\circ} \mathrm{E}$ to $\left.180^{\circ} \mathrm{E}\right)$, North America $\left(25^{\circ} \mathrm{N}\right.$ to $60^{\circ} \mathrm{N}, 145^{\circ} \mathrm{W}$ to $\left.50^{\circ} \mathrm{W}\right)$ and Northern Hemisphere regions $\left(20^{\circ} \mathrm{N}\right.$ to $\left.90^{\circ} \mathrm{N}\right)$.

observations. Therefore the total error in the USDA SCAN observations is about $0.07 \mathrm{~m}^{3} \mathrm{~m}^{-3}$.

A comparison has been made of the UM soil moisture analyses, from both the Control and Test experiments of trial 1, with USDA SCAN observations for the June to July 2009 period. Reichle et al. (2007) have also used USDA SCAN observations for verification. 91 USDA SCAN stations have sufficient data for the June to July 2009 period for a comparison. For each station, the standard deviation (SD), RMS, Bias and Correlation between the UM analyses and USDA SCAN observations are calculated. The USDA SCAN observations are used only for verification and thus have independent errors from the UM. In addition, exactly the same USDA SCAN observations are used to verify both the Test and Control experiments. Assimilation of bias corrected satellite derived surface soil moisture measurements is expected to reduce the random errors in the UM soil moisture analyses. Therefore, some impact on SD, RMS and Correlation is expected. The SD is a measure of the random errors in both the UM and USDA SCAN observations while the RMS is a measure of random errors and biases in both the UM and USDA SCAN observations. Figure 11 shows that for most
US regions, the assimilation of ASCAT surface soil wetness reduces the random difference between the UM soil moisture analyses and the USDA SCAN observations. The exception is the East coast region of the US where more USDA SCAN stations show an increase in the SD. The explanation for this is that there is greater vegetation cover over the East coast region and consequently the ASCAT surface soil wetness is likely to be less accurate there.

Very limited quality control is applied at source to measurements from USDA SCAN stations and it is thought that, at least for older measurements, there are significant problems with the data (see Reichle et al., 2007). Therefore, a simple objective quality control (QC) scheme has been implemented to identify USDA SCAN stations where the soil moisture sensors may be malfunctioning. The objective QC scheme rejects USDA SCAN stations where in either the Test or Control experiment, the correlation is less than 0.3 or the SD is higher than $0.1 \mathrm{~m}^{3} \mathrm{~m}^{-3}$ or the RMS is higher than $0.2 \mathrm{~m}^{3} \mathrm{~m}^{-3}$. The objective QC of the USDA SCAN stations is rather strict and has probably removed some good stations. The objective QC of the USDA SCAN stations does not alter the conclusions of this paper. 60 USDA SCAN stations pass 

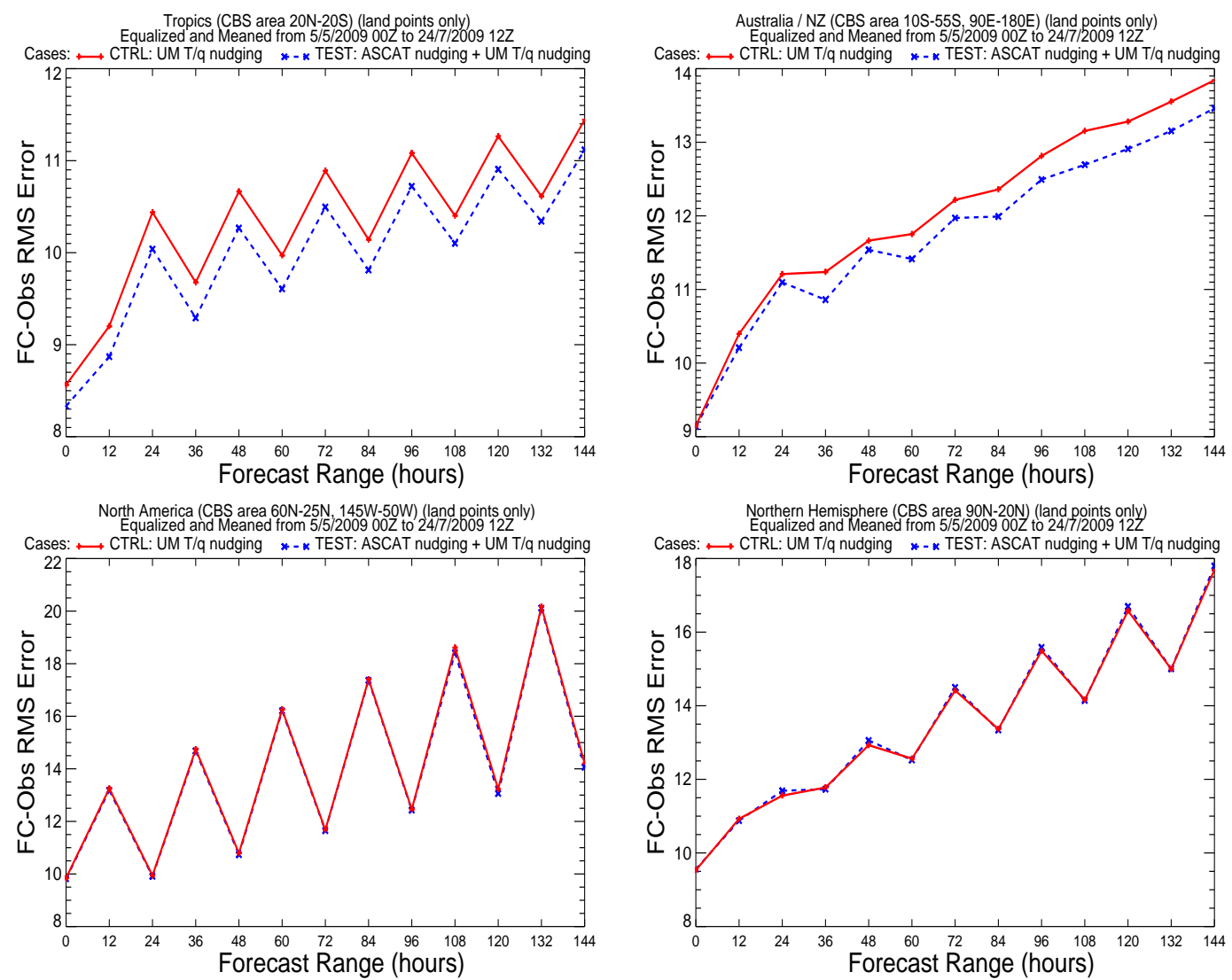

Fig. 9. Trial 1 verification of UM screen relative humidity forecasts against observations for land points only and the time period 5 May 2009 to 24 July 2009. The solid red lines (dashed blue lines) show RMS differences for the Control experiment (test experiment that also assimilates ASCAT surface soil wetness measurements). Results are shown for the tropics $\left(20^{\circ} \mathrm{S}\right.$ to $\left.20^{\circ} \mathrm{N}\right)$, Australia $\left(55^{\circ} \mathrm{S}\right.$ to $10^{\circ} \mathrm{S}, 90^{\circ} \mathrm{E}$ to $\left.180^{\circ} \mathrm{E}\right)$, North America $\left(25^{\circ} \mathrm{N}\right.$ to $60^{\circ} \mathrm{N}, 145^{\circ} \mathrm{W}$ to $\left.50^{\circ} \mathrm{W}\right)$ and Northern Hemisphere regions $\left(20^{\circ} \mathrm{N}\right.$ to $\left.90^{\circ} \mathrm{N}\right)$.

the QC (Fig. 12). Table 1 shows the verification statistics both with and without QC. The uncertainty in the verification statistics is also given using the $95 \%$ confidence intervals. The verification statistics suggest that assimilation of ASCAT surface soil wetness improves the agreement of the UM soil moisture analyses with the USDA SCAN observations (see also Fig. 11). Appendix A describes the equations used to calculate the verification statistics.

\section{Operational implementation}

Assimilation of ASCAT surface soil wetness has been implemented operationally at the Met Office in the global UM at Parallel Suite 24 (PS24) that started in May 2010 and became operational in July 2010. The operational scheme uses the value $K=0.2$ in Eq. (9). As is usual, PS24 combines together a number of model changes. In particular PS24 implemented a new cloud parameterisation scheme as well as changes to the radiation parameterisation and aerosol climatology. Since these changes will all have a significant impact on model performance, it is not possible to ascribe improvements at PS24 to any particular change.

\section{Conclusions}

We have developed a simple and computationally cheap analysis method to assimilate ASCAT surface soil wetness measurements, that has been implemented operationally. The chief strength of the method presented here is that it allows the assimilation of satellite derived surface soil moisture with screen level observations of temperature and humidity for soil moisture analysis. Our trial results indicate that assimilation of ASCAT surface soil wetness has a positive benefit on forecasts of screen temperature and humidity for the tropics, North America and Australia. A comparison with ground based observations of soil moisture indicates that generally assimilation of ASCAT surface soil wetness improves the agreement between in-situ and model soil moisture. Other research has found only a modest, often neutral, impact on weather forecasts from assimilating surface soil moisture measurements. This is the case even when complex 

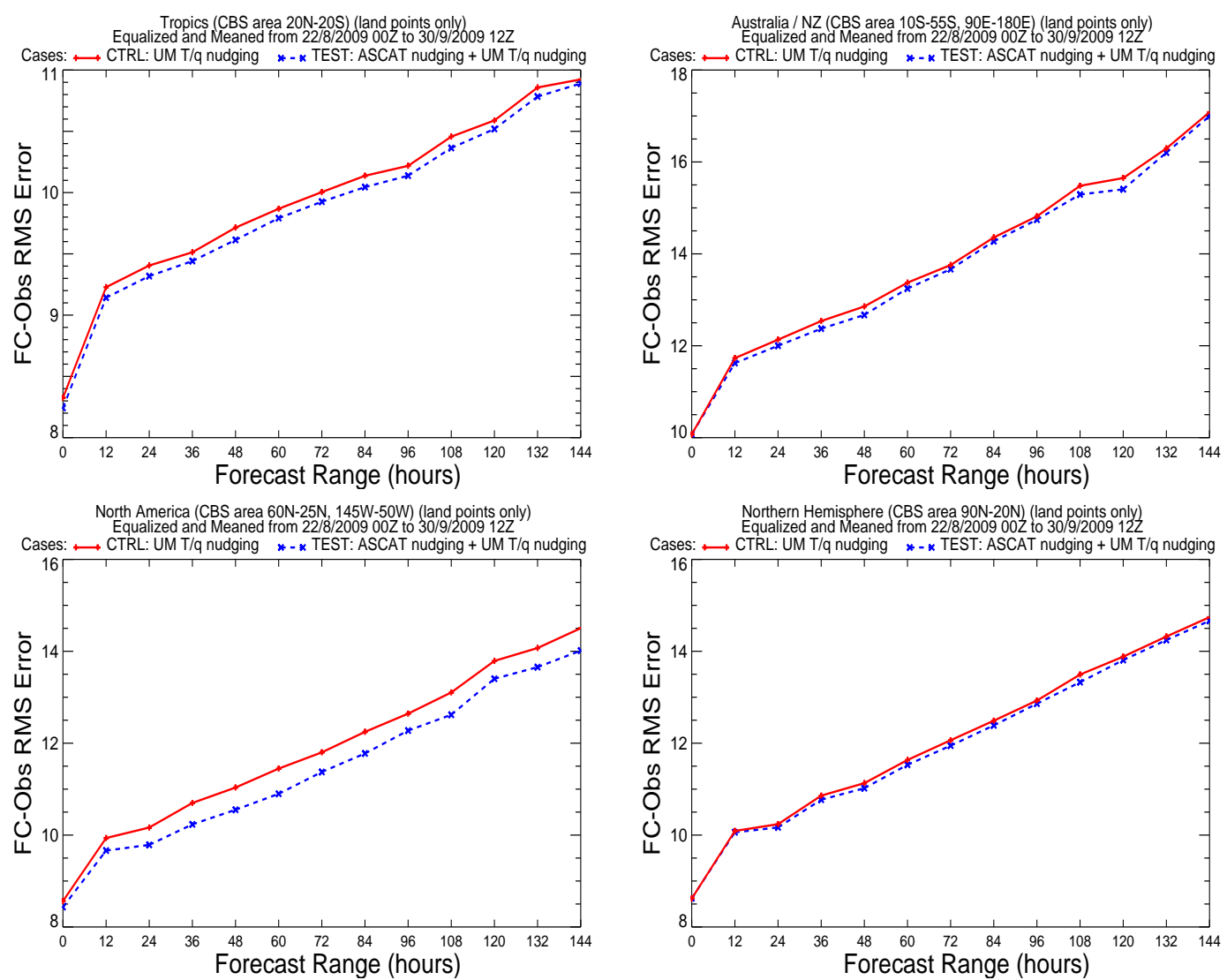

Fig. 10. Trial 2 verification of UM screen relative humidity forecasts against observations for land points only and the time period 22 August 2009 to 30 September 2009. The solid red lines (dashed blue lines) show RMS differences for the control experiment (test experiment that also assimilates ASCAT surface soil wetness measurements). Results are shown for the tropics $\left(20^{\circ} \mathrm{S}\right.$ to $\left.20^{\circ} \mathrm{N}\right)$, Australia $\left(55^{\circ} \mathrm{S}\right.$ to $10^{\circ} \mathrm{S}, 90^{\circ} \mathrm{E}$ to $\left.180^{\circ} \mathrm{E}\right)$, North America $\left(25^{\circ} \mathrm{N}\right.$ to $60^{\circ} \mathrm{N}, 145^{\circ} \mathrm{W}$ to $\left.50^{\circ} \mathrm{W}\right)$ and Northern Hemisphere regions $\left(20^{\circ} \mathrm{N}\right.$ to $\left.90^{\circ} \mathrm{N}\right)$.

Kalman Filter based approaches have been used for the soil moisture analysis.

The simple analysis method presented here uses the satellite data to only correct the model surface soil moisture. It is unclear whether this is a significant disadvantage since the land surface model will propagate surface changes to the deeper soil layers. Walker et al. (2001) have performed a theoretical study using perfect synthetic surface soil moisture observations to compare a direct insertion technique with an Extended Kalman Filter (EKF) for the analysis of a vertical soil moisture profile. For the idealised test case, both methods are found to give good results although the EKF converges more quickly to the known truth. The ability of surface soil moisture measurements to update the model root zone soil moisture will be determined by the strength of coupling between the surface and root zone soil moisture and this will depend on many factors and is still an active area of research (see for example Kumar et al., 2009). Draper et al. (2011) have used an EKF to assimilate together both surface soil moisture and screen level observations. They find that the screen level observations primarily constrain the model root zone soil moisture with the surface soil moisture observations providing a much weaker constraint. Work is also underway at the Met Office and Australian Government Bureau of Meteorology on the development of a new land DA system based around the Met Office off-line land surface model and the EKF. The new land DA system is expected to be able to make optimal use of a wide variety of observation types such as screen level observations and satellite data and to propagate information from the surface into the deeper soil layers.

The soil moisture variations in the top $\simeq 1 \mathrm{~cm}$ are much more pronounced than at a soil depth of $5 \mathrm{~cm}$. The topmost $\simeq 1 \mathrm{~cm}$ layer of the soil is subjected to much more rapid drying and wetting. Albergel et al. (2009) give an example of a rainfall event which leads to a rapid increase in the ASCAT soil moisture estimate. Whereas at a depth of $5 \mathrm{~cm}$ the increase in soil moisture only occurs a day after the rainfall event. Since the UM top soil layer has a thickness of $10 \mathrm{~cm}$ it may be more appropriate to use an exponential filter to estimate the ASCAT soil water index (SWI) for the top $10 \mathrm{~cm}$ of soil (Albergel et al., 2008; Brocca et al., 2010a) 
Table 1. Verification statistics for trial 1 of UM level 1 soil moisture analyses compared with in-situ USDA SCAN soil moisture observations. The Test experiment assimilates ASCAT surface soil wetness measurements while the Control experiment doesn't use ASCAT measurements. Results are shown both with and without an objective quality control of the USDA SCAN stations. The verification shows that assimilation of ASCAT surface soil wetness improves the agreement between the UM soil moisture analyses and USDA SCAN in-situ soil moisture observations, this is the case regardless of whether the USDA SCAN stations are quality controlled.

\begin{tabular}{lccccc}
\hline & Test experiment & \multicolumn{3}{c}{ Control experiment } & \multicolumn{3}{l}{ Number of USDA SCAN stations } \\
& ASCAT assim. & No ASCAT assim. & Better & Same & Worse \\
\hline \multicolumn{2}{l}{ With objective quality control of USDA SCAN stations } & & & \\
$\mathrm{SD}\left(\mathrm{m}^{3} \mathrm{~m}^{-3}\right)$ & $0.041 \pm 0.003$ & $0.046 \pm 0.003$ & 45 & 1 & 14 \\
$\mathrm{RMS}\left(\mathrm{m}^{3} \mathrm{~m}^{-3}\right)$ & $0.075 \pm 0.007$ & $0.082 \pm 0.008$ & 38 & 1 & 21 \\
Correlation & $0.79 \pm 0.01$ & $0.73 \pm 0.02$ & 25 & 5 & 30 \\
Bias $\left(\mathrm{m}^{3} \mathrm{~m}^{-3}\right)$ & $0.01 \pm 0.02$ & $0.01 \pm 0.02$ & 24 & 9 & 27 \\
Without any quality control of USDA SCAN stations & & & \\
SD $\left(\mathrm{m}^{3} \mathrm{~m}^{-3}\right)$ & $0.045 \pm 0.003$ & $0.051 \pm 0.004$ & 62 & 2 & 27 \\
RMS $\left(\mathrm{m}^{3} \mathrm{~m}^{-3}\right)$ & $0.108 \pm 0.011$ & $0.114 \pm 0.011$ & 55 & 2 & 34 \\
Correlation & $0.59 \pm 0.02$ & $0.52 \pm 0.02$ & 41 & 5 & 45 \\
Bias $\left(\mathrm{m}^{3} \mathrm{~m}^{-3}\right)$ & $0.03 \pm 0.02$ & $0.03 \pm 0.02$ & 41 & 15 & 35 \\
\hline
\end{tabular}

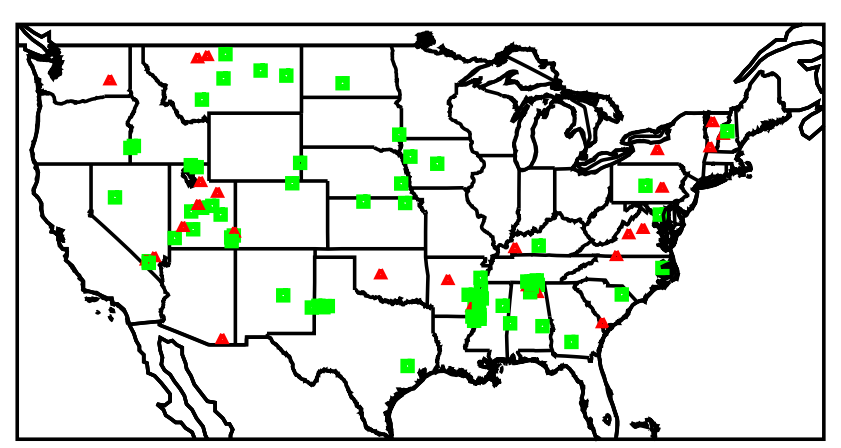

Fig. 11. Location of USDA SCAN stations measuring soil moisture. Green squares (red triangles) show locations where ASCAT surface soil wetness assimilation reduces (increases) the random difference (SD) between the UM level 1 soil moisture analyses and USDA SCAN in-situ soil moisture observations. Most locations show an improvement in the UM soil moisture analyses (green squares). However, a degradation of the UM soil moisture analyses for the US East coast is suggested by the concentration of red triangles in that area.

and assimilate the SWI instead of the ASCAT surface soil wetness $\left(m_{\mathrm{S}}\right)$. Brocca et al. (2010a) shows that in-situ soil moisture observations at a depth of $10 \mathrm{~cm}$ have a higher correlation with SWI than with $m_{\mathrm{s}}$. However, the major problem with using an exponential filter is the determination of the "characteristic time length" parameter $T$. Albergel et al. (2008) find that the optimal value of $T$ varies from location to location and year to year. Brocca (personal communication) has suggested using a global constant value of $T=4$ or 5 days. We plan future trials investigating the assimilation of SWI.

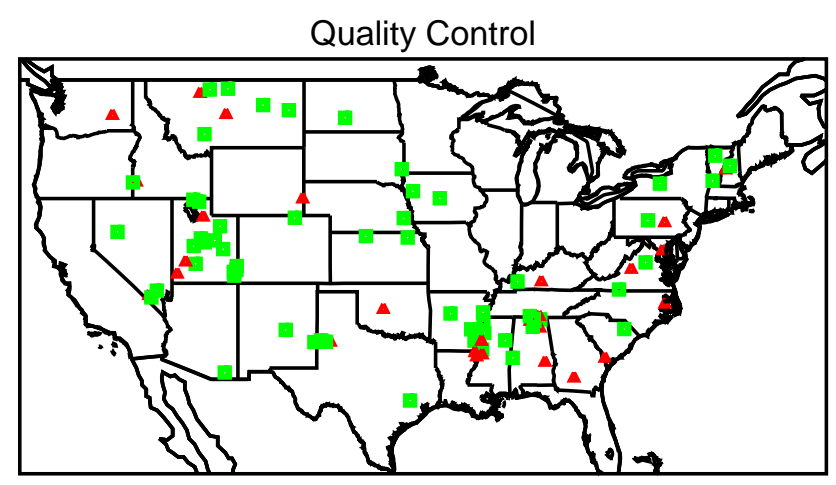

Fig. 12. Green squares (red triangles) show USDA SCAN stations passed (failed) by the objective quality control scheme. The objective quality control scheme is used during the calculation of the verification statistics shown in Table 1.

To obtain robust estimates of the bias correction parameters requires appropriate long time-series of model and satellite data. This is challenging since NWP models are updated frequently (typically 4 times a year at the Met Office) and consequently the climatology of the model soil moisture is not constant for long time periods. Similarly, updates also occur to the satellite data processing algorithms, such as the changes to the ASCAT backscatter bias correction applied by EUMETSAT in May 2009 (see Fig. 4) and the upgrade to the ASCAT level 2 soil wetness algorithm in August 2011. To circumvent the difficulty in obtaining long timeseries of data we have chosen to use ERS surface soil wetness measurements and model soil moisture from GSWP2 simulations. This is the best choice that could be made at the time our ASCAT soil wetness assimilation studies started 

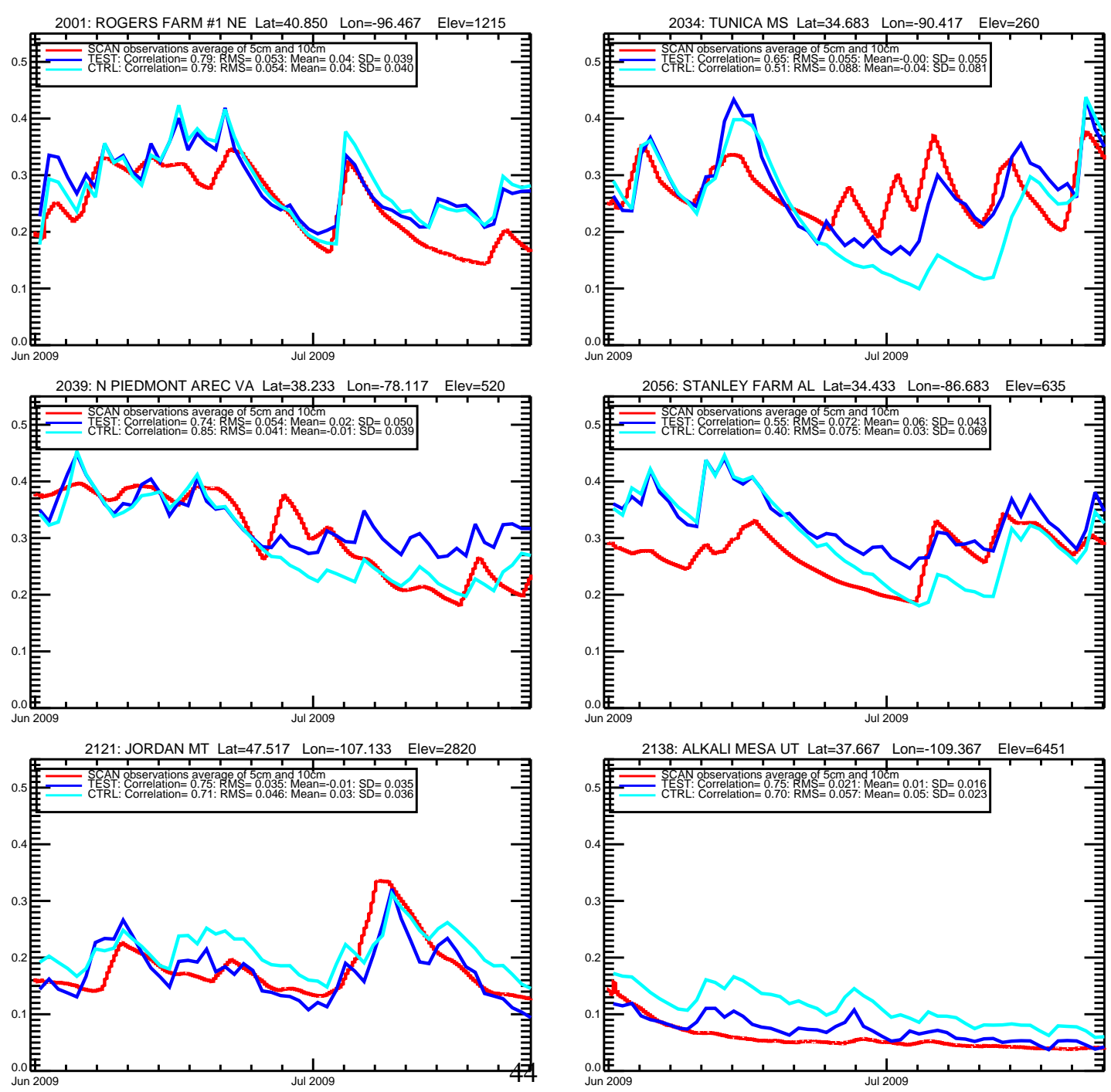

Fig. 13. Comparison of the UM level 1 soil moisture analyses with USDA SCAN observations for six selected sites during June and July 2009. The red curves shows the in-situ USDA SCAN soil moisture observations (mean of $5 \mathrm{~cm}$ and $10 \mathrm{~cm}$ measurements). The dark blue curves shows the UM level 1 soil moisture from the Test experiment of trial 1 that assimilates ASCAT surface soil wetness. The light blue curves shows the UM level 1 soil moisture from the Control experiment of trial 1 . The selected sites are in the the states of Nebraska (NE; latitude $=40.850$, longitude $=-96.467$, elevation $==1215$ feet $)$, Mississippi $(\mathrm{MS}$; latitude $=34.683$, longitude $=-90.417$, elevation $=260$ feet $)$, Virginia $(V A ;$ latitude $=38.233$, longitude $=-78.117$, elevation $=520$ feet $)$, Alabama $($ AL; latitude $=34.433$, longitude $=-86.683$, elevation $=635$ feet $)$, Montana $($ MT; latitude $=47.517$, longitude $=-107.133$, elevation $=2820$ feet $)$ and Utah $($ UT; latitude $=37.667$, longitude $=-109.367$, elevation $=6451$ feet .

in late 2008, the alternative would have been to use only a few months of data for the bias correction (as done by Mahfouf, 2010). However, additional difficulties are raised since the ERS data primarily covers the years from 1991 to 2001, while the GSWP2 simulation cover the years from 1986 to 1995. Furthermore, our assimilation trials cover periods during 2009. The mismatch in dates is likely to reduce the effectiveness of the bias correction and hence the ASCAT assimilation. As more model and satellite data becomes available the bias correction scheme will be improved in the future and most likely we will use CDF matching.
The weighting given to the ASCAT derived surface soil moisture during assimilation is determined by the parameter $K$ in Eq. (9). Currently we do not allow $K$ to vary spatially. The accuracy of the model and satellite derived surface soil moisture does vary spatially and therefore the optimal value of $K$ should also have a spatial variation. We plan to use the triple-colocation method (Dorigo et al., 2010; Scipal et al., 2008b) to derive the optimal, spatially varying, value of $\mathrm{K}$. 


\section{Appendix A}

The notation $o_{k, t, z \mathrm{~cm}}$ is used to describe an observation of volumetric soil moisture from USDA SCAN station $k$ at time $t$ and depth $z$. The average of SCAN observations at depths of $5 \mathrm{~cm}$ and $10 \mathrm{~cm}$ are used, thus we define

$o_{k, t}=0.5\left(o_{k, t, 5 \mathrm{~cm}}+o_{k, t, 10 \mathrm{~cm}}\right)$.

$m_{k, t}$ is UM level 1 volumetric soil moisture interpolated to observation space. The following equations are used to calculate the verification statistics for each station:

$\mathrm{RMS}_{k}^{2}=\frac{1}{T} \sum_{t=1}^{T}\left(m_{k, t}-o_{k, t}\right)^{2}$,

$\operatorname{Bias}_{k}=\frac{1}{T} \sum_{t=1}^{T}\left(m_{k, t}-o_{k, t}\right)=\bar{m}_{k}-\bar{o}_{k}$,

where $\bar{m}_{k}=\frac{1}{T} \sum_{t=1}^{T} m_{k, t}$ and $\bar{o}_{k}=\frac{1}{T} \sum_{t=1}^{T} o_{k, t}$.

$$
\begin{aligned}
\mathrm{SD}_{k}^{2} & =\frac{1}{T} \sum_{t=1}^{T}\left\{\left(m_{k, t}-\bar{m}_{k}\right)-\left(o_{k, t}-\bar{o}_{k}\right)\right\}^{2} \\
& =\mathrm{RMS}_{k}^{2}-\left(\operatorname{Bias}_{k}\right)^{2} .
\end{aligned}
$$

$T=54$ is the verification time period in days. The overall verification statistics are given by equations:

$\mathrm{RMS}^{2}=\frac{1}{n} \sum_{k=1}^{n} \mathrm{RMS}_{k}^{2}$

$\operatorname{Bias}=\frac{1}{n} \sum_{k=1}^{n} \operatorname{Bias}_{k}$

$\mathrm{SD}^{2}=\frac{1}{n} \sum_{k=1}^{n} \mathrm{SD}_{k}^{2}=\mathrm{RMS}^{2}-\frac{1}{n} \sum_{k=1}^{n}\left(\operatorname{Bias}_{k}\right)^{2}$

The uncertainty in the verification statistics is calculated using the $95 \%$ confidence intervals. For SD, RMS and Bias, the $95 \%$ confidence intervals are calculated as $\pm 1.96 \sigma / \sqrt{n}$ where $\sigma$ is the standard deviation of the $\mathrm{SD}_{k}, \mathrm{RMS}_{k}$ or Bias $_{k}$ station values and $n$ is the number of SCAN stations used ( $n=60$ with QC or $n=91$ without QC). For correlation, the $95 \%$ confidence intervals are calculated as $\pm 1.96\left(1-r^{2}\right) / \sqrt{N}$ (Jolliffe, 2007) where $r$ is the correlation calculated using all the observations and $N$ is the total number of observations used $(N=3240$ with QC or $N=4914$ without QC).

\section{Copyright statement}

This work is distributed under the Creative Commons Attribution 3.0 License together with an author copyright. This license does not conflict with the regulations of the Crown Copyright.

Acknowledgements. Thanks go to Klaus Scipal for help and advice with the ASCAT quality control and linear CDF matching. Thanks go to Rolf Reichle for his many constructive comments on an early draft of the paper. Thanks go to Mike Thurlow, David Walters and Paul Earnshaw for help with the pre-operational global UM NWP trial suites.

Edited by: W. Wagner

\section{References}

Albergel, C., Rdiger, C., Pellarin, T., Calvet, J.-C., Fritz, N., Froissard, F., Suquia, D., Petitpa, A., Piguet, B., and Martin, E.: From near-surface to root-zone soil moisture using an exponential filter: an assessment of the method based on in-situ observations and model simulations, Hydrol. Earth Syst. Sci., 12, 1323-1337, doi:10.5194/hess-12-1323-2008, 2008.

Albergel, C., Rüdiger, C., Carrer, D., Calvet, J.-C., Fritz, N., Naeimi, V., Bartalis, Z., and Hasenauer, S.: An evaluation of ASCAT surface soil moisture products with in-situ observations in Southwestern France, Hydrol. Earth Syst. Sci., 13, 115-124, doi:10.5194/hess-13-115-2009, 2009.

Albergel, C., Calvet, J.-C., de Rosnay, P., Balsamo, G., Wagner, W., Hasenauer, S., Naeimi, V., Martin, E., Bazile, E., Bouyssel, F., and Mahfouf, J.-F.: Cross-evaluation of modelled and remotely sensed surface soil moisture with in situ data in southwestern France, Hydrol. Earth Syst. Sci., 14, 2177-2191, doi:10.5194/hess-14-2177-2010, 2010.

Bartalis, Z.: Spaceborne Scatterometers for Change Detection over Land., Ph.D. thesis, Vienna University of Technology, available at: http://www.ipf.tuwien.ac.at/radar/ascat/publ/0024.pdf, last access: 21 July 2011, 2009.

Bartalis, Z., Wagner, W., Naeimi, V., Hasenauer, S., Scipal, K., Bonekamp, H., Figa, J., and Anderson, C.: Initial soil moisture retrievals from the METOP-A Advanced Scatterometer (ASCAT), Geophys. Res. Lett., 34, L20401, doi:10.1029/2007GL031088, 2007.

Bartalis, Z., Naeimi, V., Hasenauer, S., and Wagner, W.: ASCAT Soil Moisture Product Handbook, ASCAT Soil Moisture Report Series 15, Vienna University of Technology, Austria, 2008.

Best, M. and Maisey, P.: A physically based soil moisture nudging scheme, Hadley Centre technical note 35, Met. Office, Exeter, UK, 2002.

Brocca, L., Melone, F., Moramarco, T., Wagner, W., and Hasenauer, S.: ASCAT soil wetness index validation through in situ and modeled soil moisture data in central Italy, Remote Sens. Environ., 114, 2745-2755, doi:10.1016/j.rse.2010.06.009, 2010a.

Brocca, L., Melone, F., Moramarco, T., Wagner, W., Naeimi, V., Bartalis, Z., and Hasenauer, S.: Improving runoff prediction through the assimilation of the ASCAT soil moisture product, Hydrol. Earth Syst. Sci., 14, 1881-1893, doi:10.5194/hess-141881-2010, 2010. 
Ceballos, A., Scipal, K., Wagner, W., and Martnez-Fernndez, J.: Validation of ERS scatterometer-derived soil moisture data in the central part of the Duero Basin, Spain, Hydrol. Process., 19, 1549-1566, doi:10.1002/hyp.5585, 2005.

Davies, T., Cullen, M., Malcolm, A., Mawson, M., Staniforth, A., White, A., and Wood, N.: A new dynamical core for the Met Office's global and regional modelling of the atmosphere, Q. J. Roy. Meteorol. Soc., 131, 1759-1782, doi:10.1256/qj.04.101, 2005.

de Rosnay, P., Drusch, M., Balsamo, G., Beljaars, A., Isaksen, L., Vasiljevic, D., Albergel, C., and Scipal, K.: Advances in land data assimilation at ECMWF, in: ECMWF/GLASS Workshop on Land Surface Modelling and Data Assimilation and the Implications for Predictability, ECMWF, Reading, UK, 2009.

Dharssi, I., Vidale, P., Verhoef, A., Macpherson, B., Jones, C., and Best, M.: New soil physical properties implemented in the Unified Model at PS18, Meteorology Research and Development technical report 528, Met. Office, Exeter, UK, 2009.

Dharssi, I., Bovis, K., Macpherson, B., and Jones, C.: Assimilation of ASCAT surface soil wetness, Meteorology Research and Development technical report 548, Met. Office, Exeter, UK, 2010.

Dirmeyer, P., Gao, X., Zhao, M., Guo, Z., Oki, T., and Hanasaki, N.: The Second Global Soil Wetness Project (GSWP2): Multi-model analysis and implications for our perception of the land surface, B. Am. Meteorol. Soc., 87, 1381-1397, doi:10.1175/BAMS-87-10-1381, 2006.

Dorigo, W. A., Scipal, K., Parinussa, R. M., Liu, Y. Y., Wagner, W., de Jeu, R. A. M., and Naeimi, V.: Error characterisation of global active and passive microwave soil moisture datasets, Hydrol. Earth Syst. Sci., 14, 2605-2616, doi:10.5194/hess-142605-2010, 2010.

Dorigo, W. A., Wagner, W., Hohensinn, R., Hahn, S., Paulik, C., Xaver, A., Gruber, A., Drusch, M., Mecklenburg, S., van Oevelen, P., Robock, A., and Jackson, T.: The International Soil Moisture Network: a data hosting facility for global in situ soil moisture measurements, Hydrol. Earth Syst. Sci., 15, 1675-1698, doi:10.5194/hess-15-1675-2011, 2011.

Draper, C., Walker, J., Steinle, P., de Jeu, R., and Holmes, T.: An evaluation of AMSR-E derived soil moisture over Australia, Remote Sens. Environ., 113, 703-710, doi:10.1016/j.rse.2008.11.011, 2009.

Draper, C., Mahfouf, J., and Walker, J.: Root zone soil moisture from the assimilation of screen-level variables and remotely sensed soil moisture, J. Geophys. Res., 116, D02127, doi:10.1029/2010JD013829, 2011.

Drusch, M.: Initializing numerical weather prediction models with satellite-derived surface soil moisture: Data assimilation experiments with ECMWF's integrated forecast system and the TMI soil moisture data set, J. Geophys. Res., 112, D03102, doi:10.1029/2006JD007478, 2007.

Drusch, M. and Viterbo, P.: Assimilation of Screen-Level Variables in ECMWF's Integrated Forecast System: A Study on the Impact on the Forecast Quality and Analyzed Soil Moisture, Mon. Weather Rev., 135, 300-314, doi:10.1175/MWR3309.1, 2007.

Drusch, M., Wood, E., and Gao, H.: Observation operators for the direct assimilation of TRMM microwave imager retrieved soil moisture, Geophys. Res. Lett., 32, L15403, doi:10.1029/2005GL023623, 2005.

Essery, R., Best, M., and Cox, P.: MOSES 2.2 technical documentation, Hadley Centre technical note 30, Met. Office, Exeter, UK,
2001.

Famiglietti, J., Ryu, D., Berg, A., Rodell, M., and Jackson, T.: Field observations of soil moisture variability across scales, Water Resour. Res., 44, W01423, doi:10.1029/2006WR005804, 2008.

FAO, IIASA, ISRIC, ISS-CAS, and JRC: Harmonised world soil database (version 1.0), Tech. rep., FAO, Rome, Italy and IIASA, Laxenburg, Austria, 2008.

Giard, D. and Bazile, E.: Implementation of a new assimilation scheme for soil and surface variables in a global NWP model, Mon. Weather Rev., 128, 997-1015, 2000.

Hess, R., Lange, M., and Wergen, W.: Evaluation of the variational soil moisture assimilation scheme at Deutscher Wetterdienst, Q. J. Roy. Meteorol. Soc., 134, 1499-1512, doi:10.1002/qj.306, 2008.

Jackson, T., Cosh, M., Bindlish, R., Starks, P., Bosch, D., Seyfried, M., Goodrich, D., Moran, M., and Du, J.: Validation of Advanced Microwave Scanning Radiometer Soil Moisture Products, IEEE T. Geosci. Remote, 48, 4256-4272, 2010.

Jolliffe, I.: Uncertainty and inference for verification measures, Weather and Forecasting, 22, 637-650, doi:10.1175/WAF989.1, 2007.

Kerr, Y., Waldteufel, P., Wigneron, J., Martinuzzi, J., Font, J., and Berger, M.: Soil moisture retrieval from space: The Soil Moisture and Ocean Salinity (SMOS) mission, IEEE T. Geosci. Remote, 39, 1729-1735, doi:10.1109/36.942551, 2001.

Koster, R., Guo, Z., Yang, R., Dirmeyer, P., Mitchell, K., and Puma, M.: On the nature of soil moisture in land surface models, J. Climate, 22, 4322-4335, 2009.

Koster, R. D., Sud, Y. C., Guo, Z., Dirmeyer, P. A., Bonan, G., Oleson, K. W., Chan, E., Verseghy, D., Cox, P., Davies, H., Kowalczyk, E., Gordon, C. T., Kanae, S., Lawrence, D., Liu, P., Mocko, D., Lu, C.-H., Mitchell, K., Malyshev, S., McAvaney, B., Oki, T., Yamada, T., Pitman, A., Taylor, C. M., Vasic, R., and Xue, Y.: GLACE: The Global LandAtmosphere Coupling Experiment. Part I: Overview, J. Hydrometeorol., 7, 590-610, doi:10.1175/JHM510.1, 2006.

Kumar, S. V., Reichle, R. H., Koster, R. D., Crow, W. T., and PetersLidard, C. D.: Role of Subsurface Physics in the Assimilation of Surface Soil Moisture Observations, J. Hydrometeorol., 10, 1534-1547, doi:10.1175/2009JHM1134.1, 2009.

Li, L., Gaiser, P., Gao, B., Bevilacqua, R., Jackson, T., Njoku, E., Rudiger, C., Calvet, J., and Bindlish, R.: WindSat global soil moisture retrieval and validation, IEEE T. Geosci. Remote, 48, 2224-2241, 2010.

Loew, A. and Schlenz, F.: A dynamic approach for evaluating coarse scale satellite soil moisture products, Hydrol. Earth Syst. Sci., 15, 75-90, doi:10.5194/hess-15-75-2011, 2011.

Lorenc, A. and Hammon, O.: Objective quality control of observations using Bayesian methods. Theory, and a practical implementation, Q. J. Roy. Meteorol. Soc., 114, 515-543, doi:10.1002/qj.49711448012, 1988.

Mahfouf, J.: Assimilation of satellite-derived soil moisture from ASCAT in a limited-area NWP model, Q. J. Roy. Meteorol. Soc., 136, 784-798, doi:10.1002/qj.602, 2010.

Miller, D. and White, R.: A conterminous United States multilayer soil characteristics dataset for regional climate and hydrology modeling, Earth Interactions, 2, 1-26, doi:10.1175/10873562(1998)002<0001:ACUSMS > 2.3.CO;2, 1998.

Miralles, D. G., Crow, W. T., and Cosh, M. H.: Estimating Spa- 
tial Sampling Errors in Coarse-Scale Soil Moisture Estimates Derived from Point-Scale Observations, J. Hydrometeorol., 11, 1423-1429, doi:10.1175/2010JHM1285.1, 2010.

Naeimi, V., Scipal, K., Bartalis, Z., Hasenauer, S., and Wagner, W.: An improved soil moisture retrieval algorithm for ERS and METOP scatterometer observations, IEEE T. Geosci. Remote, 47, 1999-2013, doi:10.1109/TGRS.2008.2011617, 2009.

Njoku, E., Jackson, T., Lakshmi, V., Chan, T., and Nghiem, S.: Soil moisture retrieval from AMSR-E, IEEE T. Geosci. Remote, 41, 215-229, 2003.

Owe, M., de Jeu, R., and Holmes, T.: Multisensor historical climatology of satellite-derived global land surface moisture, J. Geophys. Res. (Earth Surface), 113, 01002, 2008.

Pullen, S., Rooney, G., and Jones, C.: Using satellite-derived snow cover data to implement a snow analysis in the Met Office global NWP model, J. Appl. Meteorol. Climatol., 50, 958-973, doi:10.1175/2010JAMC2527.1, 2010.

Rawlins, F., Ballard, S., Bovis, K., Clayton, A., Li, D., Inverarity, G., Lorenc, A., and Payne, T.: The Met Office global fourdimensional variational data assimilation scheme, Q. J. Roy. Meteorol. Soc., 133, 347-362, doi:10.1002/qj.32, 2007.

Reichle, R. and Koster, R.: Bias reduction in short records of satellite soil moisture, Geophys. Res. Lett., 31, L19501, doi:10.1029/2004GL020938, 2004.

Reichle, R., Koster, R., Dong, J., and Berg, A.: Global soil moisture from satellite observations, land surface models, and ground data: Implications for data assimilation, J. Hydrometeorol., 5, 430-442, doi:10.1175/15257541(2004)005<0430:GSMFSO>2.0.CO;2, 2004.

Reichle, R., Koster, R., Liu, P., Mahanama, S., Njoku, E., and Owe, M.: Comparison and assimilation of global soil moisture retrievals from the Advanced Microwave Scanning Radiometer for the Earth Observing System (AMSR-E) and the Scanning Multichannel Microwave Radiometer (SMMR), J. Geophys. Res., 112, D09108, doi:10.1029/2006JD008033, 2007.
Rudiger, C., Calvet, J., Gruhier, C., Thomas, H., De Jeu Richard, A., and Wagner, W.: An intercomparison of ERS-Scat and AMSR-E soil moisture observations with model simulations over France, J. Hydrometeorol., 10, 431-448, doi:10.1175/2008JHM997.1, 2009.

Scipal, K.: Global soil moisture retrieval from ERS scatterometer data., Ph.D. thesis, Vienna University of Technology, available at: http://www.ipf.tuwien.ac.at/radar/ascat/publ/0014.pdf, last access: 15 March 2011, 2002.

Scipal, K., Drusch, M., and Wagner, W.: Assimilation of a ERS scatterometer derived soil moisture index in the ECMWF numerical weather prediction system, Adv. Water Resour., 31, 11011112, doi:10.1016/j.advwatres.2008.04.013, 2008a.

Scipal, K., Holmes, T., De Jeu, R., Naeimi, V., and Wagner, W.: A possible solution for the problem of estimating the error structure of global soil moisture data sets, Geophys. Res. Lett., 35, L24403, doi:10.1029/2008GL035599, 2008b.

Seuffert, G., Wilker, H., Viterbo, P., Drusch, M., and Mahfouf, J.: The Usage of Screen-Level Parameters and Microwave Brightness Temperature for Soil Moisture Analysis, J. Hydrometeorol., 5, 516-531, 2004.

Seyfried, M. and Murdock, M.: Measurement of soil water content with a 50-MHz soil dielectric sensor, Soil Sci. Soc. Am. J., 68, 394-403, 2004.

Seyfried, M., Grant, L., Du, E., and Humes, K.: Dielectric loss and calibration of the Hydra Probe soil water sensor, Vadose Zone J., 4, 1070-1079, doi:10.2136/vzj2004.0148, 2005.

van Genuchten, M.: A closed-form equation for predicting the hydraulic conductivity of unsaturated soils, Soil Sci. Soc. Am. J, 44, 892-898, 1980.

Wagner, W., Lemoine, G., and Rott, H.: A method for estimating soil moisture from ERS scatterometer and soil data, Remote Sens. Environ., 70, 191-207, doi:10.1016/S00344257(99)00036-X, 1999.

Walker, J. P., Willgoose, G. R., and Kalma, J. D.: One-dimensional soil moisture profile retrieval by assimilation of near-surface observations: a comparison of retrieval algorithms, Adv. Water Resour., 24, 631-650, doi:10.1016/S0309-1708(00)00043-9, 2001. 